This item was submitted to Loughborough's Research Repository by the author.

Items in Figshare are protected by copyright, with all rights reserved, unless otherwise indicated.

\title{
Comprehensive evaluation of hydrological drought and its relationships with meteorological drought in the Yellow River basin, China
}

\section{PLEASE CITE THE PUBLISHED VERSION}

https://doi.org/10.1016/j.jhydrol.2020.124751

\section{PUBLISHER}

Elsevier BV

VERSION

AM (Accepted Manuscript)

\section{PUBLISHER STATEMENT}

This paper was accepted for publication in the journal Journal of Hydrology and the definitive published version is available at https://doi.org/10.1016/j.jhydrol.2020.124751.

\section{LICENCE}

CC BY-NC-ND 4.0

\section{REPOSITORY RECORD}

Wang, Fei, Zongmin Wang, Haibo Yang, Danyang Di, Yong Zhao, Qiuhua Liang, and Zafar Hussain. 2020. "Comprehensive Evaluation of Hydrological Drought and Its Relationships with Meteorological Drought in the Yellow River Basin, China”. Loughborough University. https://hdl.handle.net/2134/12628433.v1. 


\section{Comprehensive evaluation of hydrological drought and}

\section{2 its relationships with meteorological drought in the}

\section{Yellow River basin, China}

4 Fei Wang a, Zongmin Wang a, Haibo Yang a,*, Danyang Di ${ }^{\text {a }}$, Yong Zhao ${ }^{\text {b,*, }}$, Qiuhua

$5 \quad$ Liang ${ }^{\mathrm{c}}$, Zafar Hussain ${ }^{\text {a,d }}$

a School of Water Conservancy Engineering, Zhengzhou University, Zhengzhou 450001,

Abstract: Under the background of global warming, the acceleration of water cycle process will aggravate the risk of hydrological drought in the river basin. The Yellow River basin (YRB) is the most severely affected area by drought in China's major river basins, so it is particularly important to comprehensively evaluate the hydrological drought and explore its relationships with meteorological drought in the YRB. In this study, the Standardized Streamflow Index (SSI) was adopted as a hydrological drought index, and the evolution characteristics of hydrological drought were comprehensively evaluated in the YRB from 1961 to 2015 . The duration and severity of hydrological drought events were identified based on run theory, and the copula functions with the highest goodness of fit (GOF) were used to investigate the drought return period. Finally, the Standardized Precipitation 
Evapotranspiration index (SPEI) was adopted as a meteorological drought index, and the relationships between hydrological and meteorological drought were revealed by cross wavelet transform method. The results indicated that: (1) drought showed an increasing trend in the YRB from 1961 to 2015, while the worst drought occurred in 1997; (2) the trend characteristic of drought was different in each subzone; (3) the most severe drought lasted for 32 months, with drought severity of 43.29 , and drought return period of 23.26 years; (4) Frank-copula was considered to be the best-fitted copula function in the YRB; and (5) the cross wavelet transform illustrated that there was a positive correlation between hydrological and meteorological drought, and the phase angle relationships indicated that meteorological drought occurred earlier than hydrological drought in the YRB.

Keywords: Hydrological drought; Meteorological drought; Standardized Streamflow Index (SSI); Standardized Precipitation Evapotranspiration index (SPEI); Copula; Yellow River basin (YRB)

\section{Introduction}

Under the influence of global climate change and human activities, drought disasters occur frequently and have a great impact on the sustainable development of national economy, social production, and ecological environment (Vicente-Serrano and López-Moreno, 2005; Mishra and Singh, 2010; Esfahanian et al., 2016). Climate change and human activities have led to frequent occurrence of hydrological extreme events, which are characterized by drought and are seriously affecting human social production activities (Palmer and Räisänen, 2002). Hydrological drought refers to the phenomenon that streamflow or aquifer water level is below the normal value, and it is a simple and effective method to investigate hydrological drought by constructing hydrological drought indices (Shukla and Wood, 2008; Mishra and Singh, 2011). Since streamflow is influenced by 
underlying surface conditions and meteorological factors such as precipitation and evapotranspiration, the hydrological drought index based on streamflow change can better reflect the hydrological drought situation in the river basin. The Standardized Streamflow Index (SSI) is a drought index commonly used in hydrological drought monitoring and evaluation and has been used in different regions, with basic calculation requirement of hydrological historical streamflow data (Vicente-Serrano et al., 2012; Chen et al., 2018; Wu et al., 2018b, c; Xu et al., 2019; Wang et al., 2020). Rivera et al. (2017) adopted SSI to describe the extreme hydrological drought condition in Argentina, and found that SSI can accurately reflect the evolution characteristics of extreme hydrological drought in this region. Huang et al. (2017) used SSI to characterize hydrological drought in the Wei River basin, and found that propagation time from meteorological to hydrological drought exhibited significant seasonal characteristics, with a short propagation time in spring and summer, and a long propagation time in autumn and winter. Wu et al. (2018a) applied SSI to compare the hydrological drought in the early and late stages of reservoir operation in the Dongjiang River basin. And the results will enable us better understand the impact of human activities on the evolution of hydrological drought at multiple time scales. Lai et al. (2019) used SSI to investigate hydrological drought based on long-term satellite remote sensing precipitation data in Beijiang River basin of China, and demonstrated that SSI had good applicability in the simulation and quantitative research of hydrological drought in this basin. Peña-Gallardo et al. (2019) computed SSI for each basin of the contiguous Unites States, and revealed the complex influences of meteorological drought time-scales on hydrological droughts.

The characteristics of drought events can be quantitatively revealed after the drought index is calculated. However, previous researches on drought events mainly focused on the univariate study of drought duration or drought severity, while the univariate drought characteristic can not depict the complexity and extensive impact of drought events. A 
complete description of drought events requires multiple drought characteristic variables with certain correlation, such as drought duration, severity, and affected area (Salas et al., 2005; Yoo et al., 2012). Run theory is a time series analysis method, which is widely used in the identification of drought events (Wu et al., 2017; Zhao et al., 2017). In the process of drought identification, some serious drought events may be mixed with some non-drought events with short drought duration, resulting in a serious drought event being divided into several less-serious drought events, thus weakening the impact of the actual drought. Therefore, it is necessary to optimize the truncation level of drought identification, so as to improve the accuracy of run theory in actual drought analysis (Wang et al., 2017).

After identifying the characteristic variables of drought events based on run theory, it is useful to use copula function to combine the drought characteristic variables (Kao and Govindaraju, 2010; Mirabbasi et al., 2012). Copula function can combine multiple drought characteristic variables, which is more superior than traditional multivariate analysis method and is widely used in hydrological and meteorological field (Lee et al., 2013; Dash et al., 2019). Sklar (1959) proposed copula as a joint function, which had been widely used in hydrological drought, meteorological drought, and flood disasters. $\mathrm{Xu}$ et al. (2015) investigated the drought frequency in southwestern China based on copula, and discovered that copula was an effective method for multivariate drought frequency analysis. Vyver and Bergh (2018) examined the Normal-copula model for the joint deficit index, and verified that the Normal-copula had advantages over the traditional empirical method in drought assessment. The extensive application of copula showed that it could better combine multiple drought characteristic variables and could also be applied in many other research fields. Applying copula to drought field and choosing the best-fitted copula to identify the drought return period is of great practical significance for promoting the sustainable development of arid areas (Tosunoğlu and Onof, 2017). 
Most scholars have discussed the relationships between hydrological and

meteorological drought, and concluded that meteorological drought is the major factor leading to hydrological drought (Pandey and Ramasastri, 2001; Vidal et al., 2010; Leng et al., 2015). Long-term meteorological drought can lead to the decrease of river runoff and groundwater level. When the balance of income and expenditure of surface water and groundwater is broken, it is considered that hydrological drought begins to occur. Hydrological drought is later than meteorological drought and both drought types reflect different drought development stages. Although there are numerous drought studies using hydrological and meteorological drought indices, there are few studies on the relationships between hydrological and meteorological drought (Van Loon and Laaha, 2015; Barker et al., 2016). Thus, further comprehensive analysis of the relationships between hydrological and meteorological drought can deepen the understanding of the causes of drought, which has a very important guiding significance for deepening the study of drought (Huang et al., 2017).

Over the past decades, water resources have been over exploited in the Yellow River basin (YRB), resulting in a significant decline in surface runoff in some areas of the basin (Huang et al., 2015; Shi et al., 2017). The hydrometeorological conditions are complex and changeable in the YRB, with insufficient water resources and unbalanced precipitation distribution. The formation condition of hydrological drought is complicated, which is not only the result of comprehensive influence of climate factors and anthropogenic activities, but also related to the complex topographic features (Omer et al., 2020). The YRB is an important agricultural production base in China, and people will increase the exploitation and utilization of water resources once drought occurs, which will deepen the impact of hydrological drought (Fu et al., 2004). In addition, numerous water conservancy projects and large population density increase the complexity of hydrological drought investigation in the YRB. More recently, the hydrological drought disasters occurred frequently, with drought 
duration and intensity increasing gradually in the YRB (Shiau et al., 2007; Zhao et al., 2017; Zhu et al., 2019). Specifically, the longest river cut-off event in history occurred in the lower reaches of the YRB (226 days) in the year of 1997, which made people further realize the importance of strengthening the hydrological drought investigation (Huo et al., 1998). The vast geographical area, frequent human activities and complex hydrological conditions make the hydrological drought study more important in the YRB. Currently, a systematic research on hydrological drought and its relationships with meteorological drought has not been carried out in the YRB.

In view of this, this paper adopted SSI to comprehensively evaluate the hydrological drought in the YRB from 1961 to 2015 . The primary objectives of this study are: (1) to calculate SSI by fitting monthly streamflow data with optimal distribution function; (2) to identify drought duration and severity based on run theory, and to fit the marginal distribution functions of drought duration and severity; (3) to select the optimal copula to analyze the drought return period; and (4) to investigate the relationships between hydrological and meteorological drought by using the cross wavelet transform method. The research results can provide a scientific foundation for the evolution and prediction of hydrological drought under changing environment in the YRB.

\section{Study area and data}

The Yellow River is the second longest river in China, which flows through nine provinces and has a total drainage area of $795,000 \mathrm{~km}^{2}$ (Fig. 1). In recent years, the precipitation has decreased and the temperature has increased significantly in the YRB. Especially since the 1990s, the frequency and impact of drought have increased significantly, which has brought great risks to water resources and energy, food and ecological security in the YRB (Huang et al., 2015; Wang et al., 2018a). As the largest source of water supply in northern China, the YRB is mainly recharged by precipitation, with the total water resources accounting for only $2.6 \%$ of the total water resources in 
China. With the rapid increase of water resources utilization, the cut-off phenomenon of main stream and tributary is becoming serious, and the decline of water resources will further aggravate the contradiction between supply and demand of water resources in the YRB. How to effectively manage the gradually reduced water resources has become a great challenge for the sustainable development of the YRB. The YRB has a large geographical scope, and its elevation increases gradually from southeast to northwest. The special climatic characteristics, geographical conditions, and decreasing water resources lead to frequent occurrence of drought disasters in the YRB (Zhang et al., 2015).

In this paper, monthly streamflow data of seven typical hydrological stations in the main stream of the YRB during 1961-2015 were obtained from the Hydrological Bureau of the Yellow River Water Conservancy Commission. Since the Inner Flow region (IF) is not a catchment area and there is no streamflow data, the long-term streamflow data of seven typical hydrological stations were used to reflect the hydrological conditions of seven different catchments areas, and the average streamflow was used to reflect the hydrological conditions of the whole basin. The selected seven hydrological stations are located downstream of each catchment area, thus they can reflect hydrological information of different catchment areas (Fu et al., 2004). From upstream to downstream, these hydrological stations are Tangnaihai Station, Lanzhou Station, Toudaoguai Station, Longmen Station, Sanmenxia Station, Huayuankou Station and Lijin Station, respectively. They represent the hydrological conditions of above Longyangxia (AL), Longyangxia to Lanzhou (LL), Lanzhou to Hekou (LH), Hekou to Longmen (HL), Longmen to Sanmenxia (LS), Sanmenxia to Huayuankou (SH) and below Huayuankou (BH), respectively. The monthly precipitation and temperature data from 124 meteorological stations during 1961-2015 were obtained from the National Meteorological Information Center (NMIC) at the China Meteorological Administration (CMA) (http://data.cma.cn/). It can be seen from Fig. 1 that the 124 meteorological stations are distributed evenly and can contain the outer 
envelope of the whole basin. Additionally, the homogeneity and reliability of the meteorological data were checked by CMA before their release. After strict quality control, the data quality had been significantly improved and showed good homogeneity.

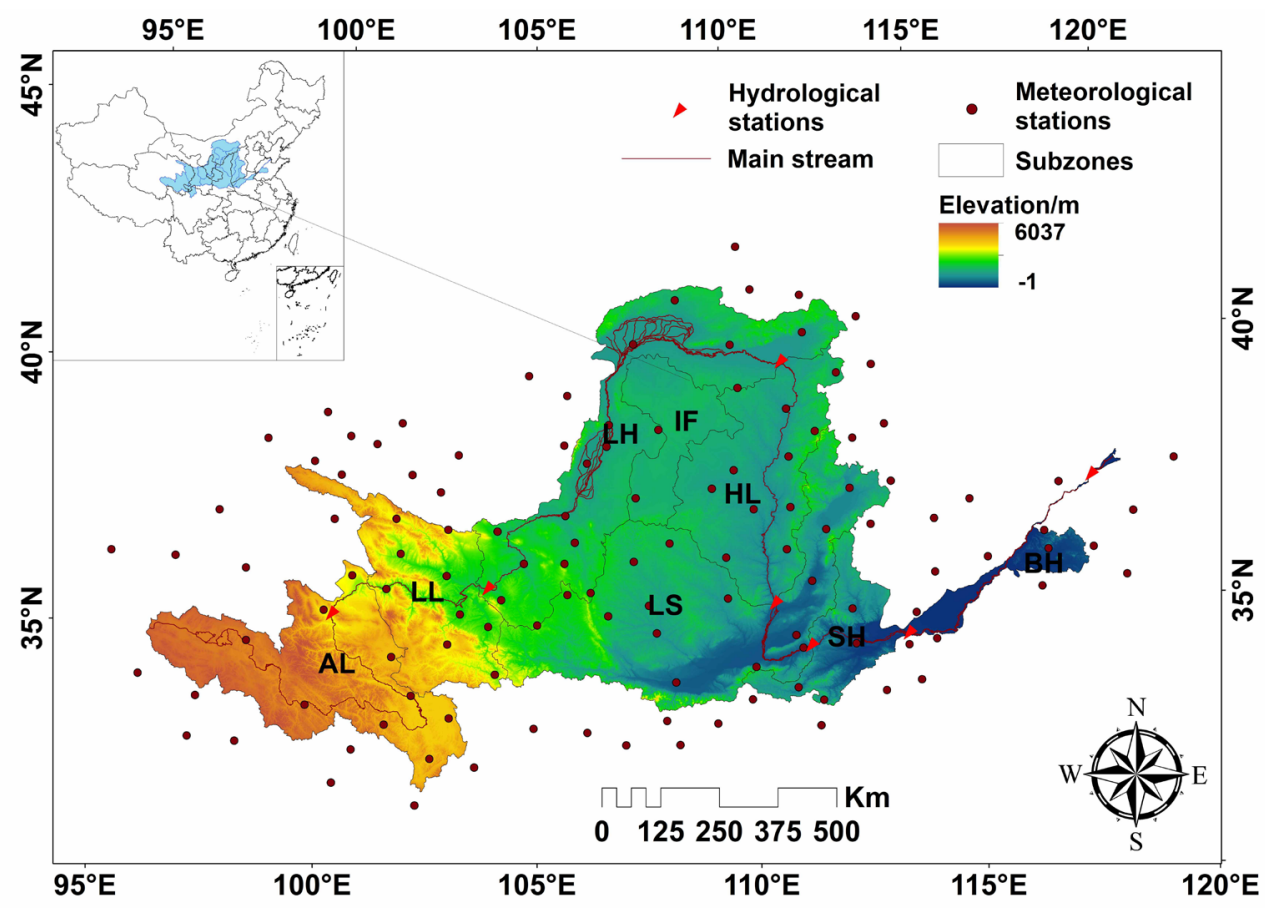

Fig. 1. The location of the meteorological and hydrological stations in the YRB.

\section{Methodology}

\subsection{Standardized streamflow index (SSI)}

The SSI was selected as a hydrological drought index in this study, and its calculation procedure was similar to that of the Standardized Precipitation Index (SPI). In the process of calculating SSI, Gamma distribution function was used to describe streamflow changes, and then normal standardization processing was carried out. However, due to the influences of human activities, climatic and geographical factors, the streamflow distributions have regional differences, so it is necessary to check the probability distribution of streamflow and select the optimal distribution function to calculate SSI (Telesca et al., 2012; Bloomfield and Marchant, 2013; Chen et al., 2018). We initially fitted six three-parameter Lognormal (Logn), Generalized Pareto (GP), Pearson Type III (P-III), Log-Logistic (Log-L), General Extreme Value (GEV), and Weibull (Wbl) distributions to the monthly 
streamflow data by maximum likelihood estimation method (Vicente-Serrano et al., 2012).

These distributions were selected because they could accommodate all magnitudes of non-negative skewness from zero to severe (Table 1). After fitting the distribution of streamflow data in each month, the Kolmogorov-Smirnov (K-S), Anderson-Darling (A-D) and Akaike Information Criterion (AIC) test method were adopted to test the fitting results (Sherly et al., 2016). We selected the optimal distribution function that showed the smallest statistic $d$ value calculated by K-S test, statistic $a$ value calculated by A-D test, and AIC value. The distribution function was eliminated if the statistic $d$ value was greater than the critical $D$ value $(0.18)$ or the statistic $a$ value was greater than the critical $A$ value $(2.50)$. SSI can be calculated after selecting the optimal distribution function of streamflow, and the detailed computational processes can be referred to Vicente-Serrano et al. (2012).

\section{Table 1}

Six three-parameter distribution functions used in this research.

\begin{tabular}{cccc}
\hline Name & Cumulative Distribution Function (CDF) & Parameters & Reference \\
\hline Lognormal (Logn) & $F(x)=\Phi\left(\frac{\ln (x-\gamma)-\mu}{\sigma}\right)$ & $\mu, \sigma, \gamma$ & (Hosking, 1990) \\
Gen. Pareto (GP) & $F(x)=1-\left[1-\frac{k}{\alpha}(x-\varepsilon)\right]^{1 / k}$ & $k, \alpha, \varepsilon$ & (Hosking, 1990) \\
Pearson Type III (P-III) & $F(x)=\frac{1}{\alpha \Gamma(\beta)} \int_{\gamma}^{x}\left(\frac{x-\gamma}{\alpha}\right)^{\beta-1} e^{-\left(\frac{x-\gamma}{\alpha}\right)}$ & $\alpha, \beta, \gamma$ & (Hosking, 1990) \\
Log-Logistic (Log-L) & $F(x)=\left[1+\left(\frac{\beta}{x-\gamma}\right)^{\alpha}\right]^{-1}$ & $\alpha, \beta, \gamma$ & (Singh et al., 1993) \\
Gen. Extreme Value (GEV) & $F(x)=\exp \left(-\exp \left(k^{-1} \ln \left(1-\frac{k(x-\mu)}{\sigma}\right)\right)\right)$ & $k, \sigma, \mu$ & (Hosking et al., 1985) \\
Weibull (Wbl) & $F(x)=1-\exp \left(-\left(\frac{x-\gamma}{\beta}\right)^{\alpha}\right)$ & $\alpha, \beta, \gamma$ & (Hosking, 1986) \\
\hline
\end{tabular}

3.2. Standardized precipitation evapotranspiration index (SPEI)

214 the characteristics of spatial comparability, but also can reflect drought information at different time scales. In this paper, SPEI at different time scales can be calculated based on 
monthly precipitation and temperature data of each meteorological station. Thornthwaite method is used to calculate the evapotranspiration (Thornthwaite, 1948). Through Kriging interpolation and regional averaging, the meteorological drought conditions can be obtained in seven subzones and the whole basin. More details on the SPEI calculation can be found in Tirivarombo et al. (2018).

\subsection{The modified Mann-Kendall (MMK) trend test method}

The traditional Mann-Kendall (MK) trend test is a nonparametric statistical testing method, which is widely used to detect the trend characteristics of time series. MK method is based on the assumption that the time series are independent and random. However, the time series often have autocorrelation, which influence the significance of the test results (Huang et al., 2016). The Modified Mann-Kendall (MMK) trend test method can better eliminate the autocorrelation components in the sequence and improve the testing ability of the MK method. Therefore, this paper adopted MMK method to investigate the trend characteristics of hydrological drought on the monthly, seasonal, and annual scales in the YRB during 1961-2015. The calculation procedure of the MMK method is described in Wang et al. (2019).

\subsection{Run theory and copula-based models}

Based on the calculated SSI, the hydrological drought characteristics were depicted in the YRB (Shukla and Wood, 2008; Núñez et al., 2014; Rivera et al, 2017). Two main characteristic variables of drought events, drought duration and drought severity, were identified by using run theory. Drought duration is the duration of a drought event from its occurrence to termination, and drought severity is the absolute value of the accumulated SSI value during the drought event. In previous studies of drought identification based on run theory, the method of setting only a single truncation level was mostly used to identify drought events, which could easily reduce the accuracy of drought identification (Ayantobo 
et al., 2018). Thus, three truncation levels $\left(X_{0}=0, X_{1}=0.3\right.$, and $\left.X_{2}=0.5\right)$ were set in this study (Wang et al., 2017). The specific identification process of drought events is as follows:

(1) When the SSI value is less than $X_{1}$, it is preliminarily determined that drought occurs in this month.

(2) When the drought event lasts only one month and the corresponding SSI value is greater than $X_{2}$, it is considered that there is no drought in this month.

(3) When the time interval between two adjacent drought events is only one month and the corresponding SSI value is less than $X_{0}$ in that month, the two adjacent drought events can be merged into one drought event. The drought duration is the sum of drought duration and one month, and the drought severity is the sum of drought severity. Otherwise, they are two independent drought events.

After identifying the drought duration and severity based on run theory, it is useful to select copula function to combine the two characteristic variables. The marginal distribution function of drought duration and severity should be firstly determined, and the dependence between the two characteristic variables should be considered. Similarly, we fitted six three-parameter Logn, GP, P-III, Log-L, GEV, and Wbl distribution functions to the identified drought duration and severity. The K-S, A-D and AIC test method were adopted to determine the optimal marginal distribution function. On the premise of passing the significance test, the distribution functions with the best goodness of fit (GOF) were selected as the marginal distribution types of drought characteristic variables. In this study, maximum likelihood estimation method was used to estimate the parameters of univariate and bivariate distribution function. We adopted the commonly used bivariate theoretical copula functions, including Normal-copula, t-copula, Clayton-copula, Frank-copula, and Gumbel-copula (Lee et al., 2013). The GOF of the copula function was tested based on the root mean square error (RMSE), AIC, and Bayesian Information Criterion (BIC) between the theoretical and empirical distribution function (Fan et al., 2018). Based on the principle 
268 the optimal copula functions were established in the YRB. Copula families used in this

269 research are shown in Table 2. The calculation of drought return period can be referred to

270 Sadegh et al. (2017).

\section{$271 \quad$ Table 2}

272 Copula families used in this research.

\begin{tabular}{cccc}
\hline \multicolumn{1}{c}{ Name } & Mathematical Description & Parameter Range & Reference \\
\hline Normal-copula & $\int_{-\infty}^{\phi^{-1}(u)} \int_{-\infty}^{\phi^{-1}(v)} \frac{1}{2 \pi \sqrt{1-\theta^{2}}} \exp \left(\frac{2 \theta x y-x^{2}-y^{2}}{2\left(1-\theta^{2}\right)}\right) d x d y$ & $\theta \in[-1,1]$ & (Li et al., 2013) \\
t-copula & $\int_{-\infty}^{t_{\theta_{2}}^{-1}(u)} \int_{-\infty}^{t_{\theta_{2}}^{-1}(v)} \frac{\Gamma\left(\left(\theta_{2}+2\right) / 2\right)}{\Gamma\left(\theta_{2} / 2\right) \pi \theta_{2} \sqrt{1-\theta_{1}^{2}}}\left(1+\frac{x^{2}-2 \theta_{1} x y+y^{2}}{\theta_{2}}\right)^{\left(\theta_{2}+2\right) / 2} d x d y$ & $\theta_{1} \in[-1,1]$ and & \\
Clayton-copula & $\max \left(u^{-\theta}+v^{-\theta}-1,0\right)^{-1 / \theta}$ & (Li et al., 2013) \\
Frank-copula & $-\frac{1}{\theta} \ln \left[1+\frac{(\exp (-\theta u)-1)(\exp (-\theta v)-1)}{\exp (-\theta)-1}\right]$ & $\theta \in[-1, \infty) \backslash 0$ & (Clayton, 1978) \\
Gumbel-copula & $\exp \left\{-\left[(-\ln (u))^{\theta}+(-\ln (v))^{\theta}\right]^{1 / \theta}\right\}$ & $\theta \in R \backslash 0$ & (Li et al., 2013) \\
\hline
\end{tabular}

273

\subsection{Cross wavelet transform method}

Cross wavelet transform method is a new multi-signal and multi-scale time-frequency analysis technique developed on the basis of traditional wavelet transform (Lin et al., 2017). It can effectively analyze the correlations and reflect the phase structure and detailed characteristics between two time series in both time and frequency domains. Cross wavelet transform can measure the correlation between two sequences in the high energy region, but it is insufficient to analyze the low energy region in time-frequency space, while wavelet coherence can better reflect the correlation between two sequences in the low energy region. Cross wavelet transform and wavelet coherence are powerful methods for testing proposed relationships between two time series. Therefore, cross wavelet transform and wavelet coherence of monthly SSI and SPEI sequences were used to reveal the relationships between hydrological and meteorological drought in the YRB during 1961-2015. The detailed procedures can be referred to Grinsted et al. (2004). 


\section{Results}

\subsection{The evolutionary characteristics of hydrological drought}

The optimal distribution function of monthly streamflow is shown in Fig. 2. The empirical distribution function is a ladder diagram, which reflects the actual sample distribution. By overlapping the empirical and theoretical distribution function in each month, we can see that the selected theoretical distribution had better fitting effect and was close to the actual streamflow distribution. The GOF of all theoretical distributions passed the significance test of $\alpha=0.05$. Meanwhile, the calculated statistic $d$ value, statistic $a$ value, and AIC value were smaller, among which the statistic $d$ value and statistic $a$ value were smaller than the critical value, indicating that the optimal distribution function determined had better fitting effect on the original streamflow data. Determination of the optimal distribution function of monthly streamflow in the YRB is shown in Table 3. Similarly, the optimal distribution function can be obtained in each subzone of the YRB. The hydrological drought index SSI can be calculated by normalizing the probability of different distributions.
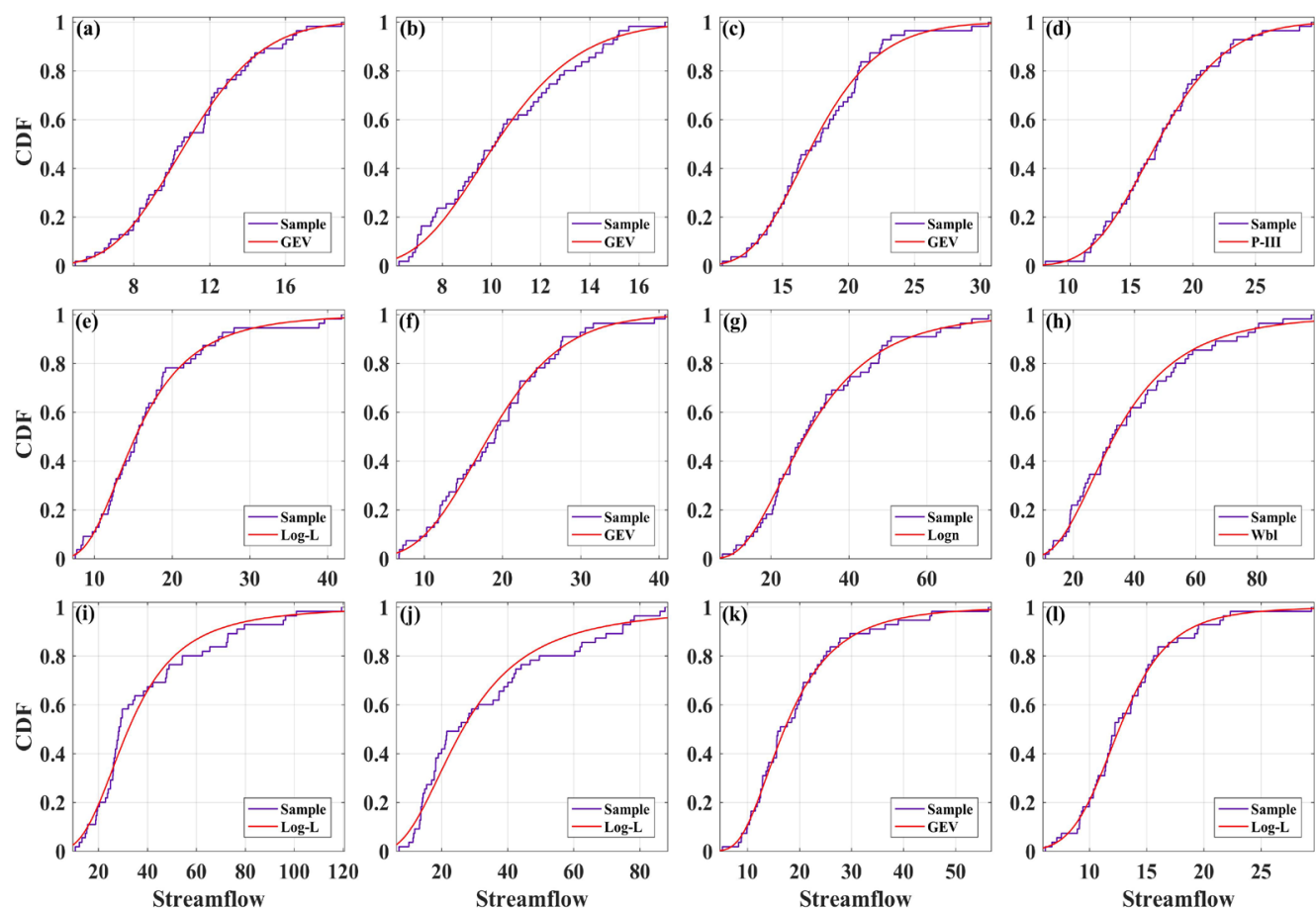
Fig. 2. The optimal distribution function of monthly streamflow $\left(10^{8} \mathrm{~m}^{3}\right)$ in the YRB. (a)-(1) denote January, February, March, April, May, June, July, August, September, October, November and December, respectively.

\section{Table 3}

Determination of the optimal distribution function of monthly streamflow in the YRB.

\begin{tabular}{cccccc}
\hline Month & Optimal distribution & $p$ & $d$ & $a$ & AIC \\
\hline January & GEV & 0.94 & 0.07 & 0.12 & -424.39 \\
February & GEV & 0.96 & 0.07 & 0.38 & -383.72 \\
March & GEV & 0.99 & 0.06 & 0.25 & -393.56 \\
April & P-III & 0.99 & 0.05 & 0.13 & -440.97 \\
May & Log-L & 0.99 & 0.06 & 0.18 & -414.23 \\
June & GEV & 0.99 & 0.06 & 0.19 & -408.85 \\
July & Logn & 0.99 & 0.06 & 0.19 & -406.10 \\
August & Wbl & 0.99 & 0.05 & 0.15 & -396.10 \\
September & Log-L & 0.35 & 0.12 & 0.59 & -319.42 \\
October & Log-L & 0.70 & 0.09 & 0.69 & -306.85 \\
November & GEV & 0.99 & 0.06 & 0.15 & -418.35 \\
December & Log-L & 0.98 & 0.06 & 0.21 & -408.59 \\
\hline
\end{tabular}

Fig. 3 illustrates the temporal evolution characteristics of hydrological drought on the monthly scale in the YRB from 1961 to 2015. The drought showed an increasing trend in the YRB, with particularly significant trend since the 1990s. The most significant upward trend of drought occurred in $\mathrm{BH}$, whilst the linear tendency rate of SSI was $-0.026 / 10 \mathrm{a}$. On the monthly scale, the most severe droughts in AL, LL, LH, HL, LS, SH, BH, and YRB occurred in November 2002, September 1997, December 1965, March 2002, November 1997, April 2003, February 1999 and November 1997, respectively; with an SSI value of $-1.94,-2.80,-2.58,-2.66,-2.53,-2.64,-3.01$ and -2.75 , respectively. It can be seen that extreme drought events were more likely to occur after the 1990s. On the annual scale, the average SSI values reached the minimum value in 1997 in LL, LH, HL, LS, SH, BH and YRB, with average SSI values of $-1.62,-1.34,-1.23,-1.38,-1.29,-1.72$ and -1.68 , respectively. Therefore, drought occurred most severely in 1997 in the YRB. On the decadal scale, drought was relatively mild in the 1960s, with average SSI values of 0.25 , $0.29,0.19,0.41,0.78,0.76,1.05$ and 0.76 , respectively (Figs. 3a-h). The most severe 
droughts occurred in the 1990s in LL and $\mathrm{BH}$, with an average SSI value of -1.02 and -0.66. And the most severe droughts occurred in the 2000s in AL, LH, HL, LS, SH, and YRB, with an average SSI value of $-0.35,-0.41,-0.57,-0.75,-0.55$ and -0.63 , respectively.

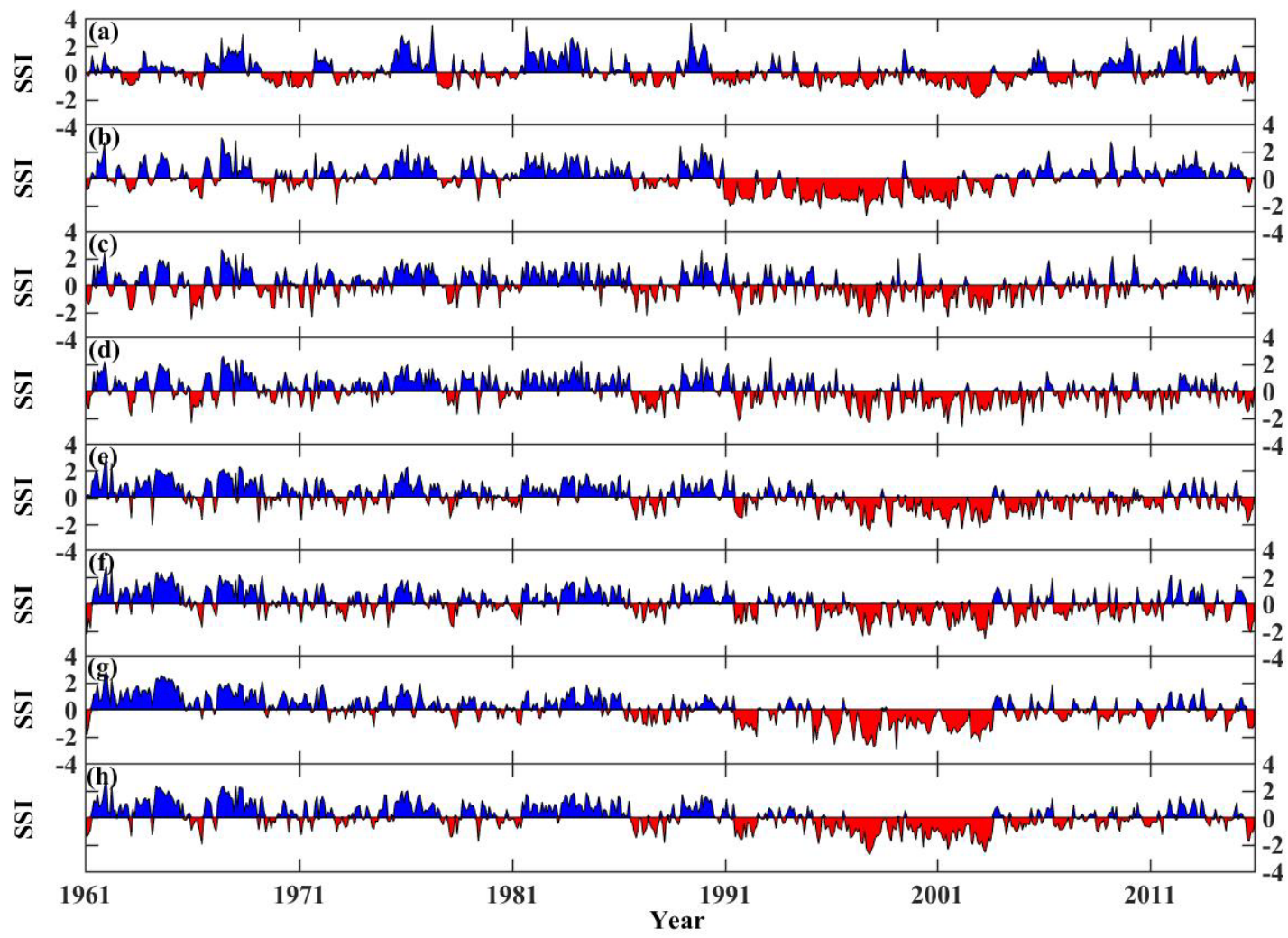

Fig. 3. Temporal evolution characteristics of hydrological drought in the YRB from 1961 to 2015. (a)-(h) denote AL, LL, LH, HL, LS, SH, BH and YRB, respectively (similar below).

SSI has the characteristics of multiple time scales and can consider the cumulative drought effects at different time scales. SSI values at different time scales (1-24 months) were calculated in detail, and Hovmoller-type maps for the temporal evolutions of hydrological drought were depicted in the YRB (Fig. 4). The drought evolution is a progressive process, and the fluctuation of SSI values at different time scales can reflect the drought variations. SSI showed a downward trend at all time scales, which indicated that drought was aggravating. Similar to the temporal characteristics of drought reflected by 
monthly SSI, drought showed an upward trend at different time scales and tended to be serious after the 1990s in the YRB. In the whole basin scale, the linear tendency rate of SSI changed gradually from $-0.021 / 10 \mathrm{a}$ (1-month scale) to $-0.036 / 10 \mathrm{a}$ (24-month scale) (Fig. $4 \mathrm{~h})$. With the increase of time scales (1-month to 24-month scale), the trend of drought aggravation was gradually obvious. The drought trend was different in each subzone, and the maximum linear tendency rate of SSI was $-0.013 / 10 \mathrm{a},-0.024 / 10 \mathrm{a},-0.031 / 10 \mathrm{a},-0.037 / 10 \mathrm{a}$, $-0.039 / 10 \mathrm{a},-0.037 / 10 \mathrm{a}$ and $-0.038 / 10 \mathrm{a}$, respectively (Figs. 4a-g).

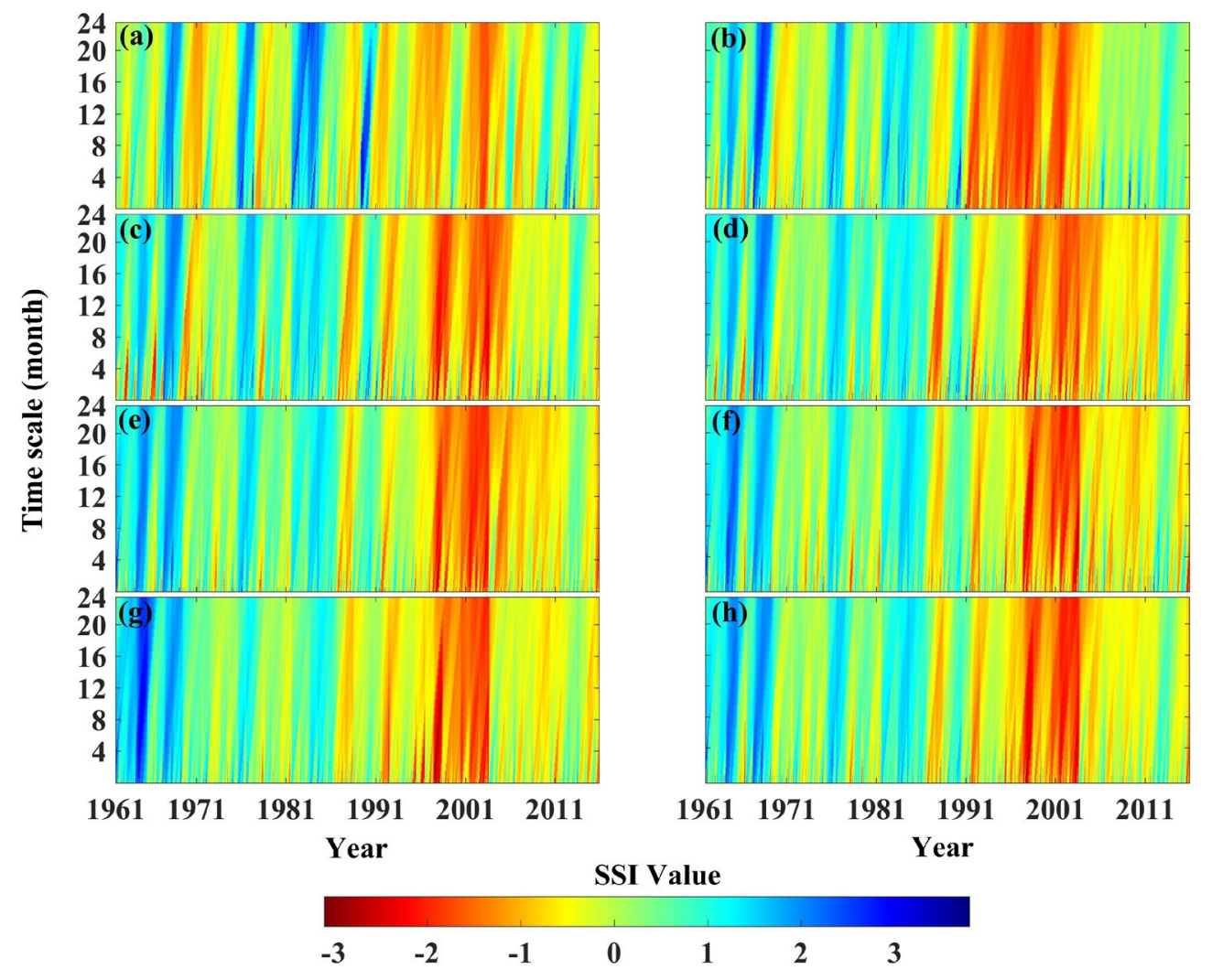

Fig. 4. Hovmoller-type maps of the hydrological drought at different timescales (1 to 24 months) in the YRB.

The trend characteristic $Z_{s}$ values of monthly, seasonal, and annual SSI based on the MMK trend test method are depicted in Fig. 5. $Z_{s}>0$ indicates a downward drought trend, and $Z_{s}<0$ indicates an upward drought trend. It can be seen that the drought trend characteristics were obviously different in each period. On the monthly scale, the trend characteristic $Z_{s}$ values in the YRB from January to December were $-0.61,0.08,-0.99$, 

$-0.99,-1.19,0.31,-1.01,-1.25,-1.15,-1.21,-1.33$ and -0.94 , respectively. The SSI showed a downward trend and drought showed an upward trend for ten months (January, March, April, May, July, August, September, October, November, and December). Additionally, the $Z_{s}$ value was less than zero in each subzone from July to November, indicating that drought was increasing in these months. On the seasonal scale, the $Z_{s}$ values in the YRB from spring to winter were $-1.21,-1.18,-1.33$ and -0.74 , respectively. Generally, drought showed an upward trend in each season, with different seasonal trend characteristics in each subzone. The $Z_{s}$ value was less than zero in summer and autumn, which indicated that drought was increasing in both seasons in each subzone. On the annual scale, the $Z_{s}$ value was -1.44 , indicating that drought was increasing in the YRB. Meanwhile, the $Z_{s}$ value was less than zero and drought was also increasing in each subzone. The trend characteristic $Z_{s}$ values failed to pass the significance test of $\alpha=0.05$, and most of $Z_{s}$ values were less than zero, indicating that drought generally showed a non-significant upward trend in the YRB (Fig. 5).

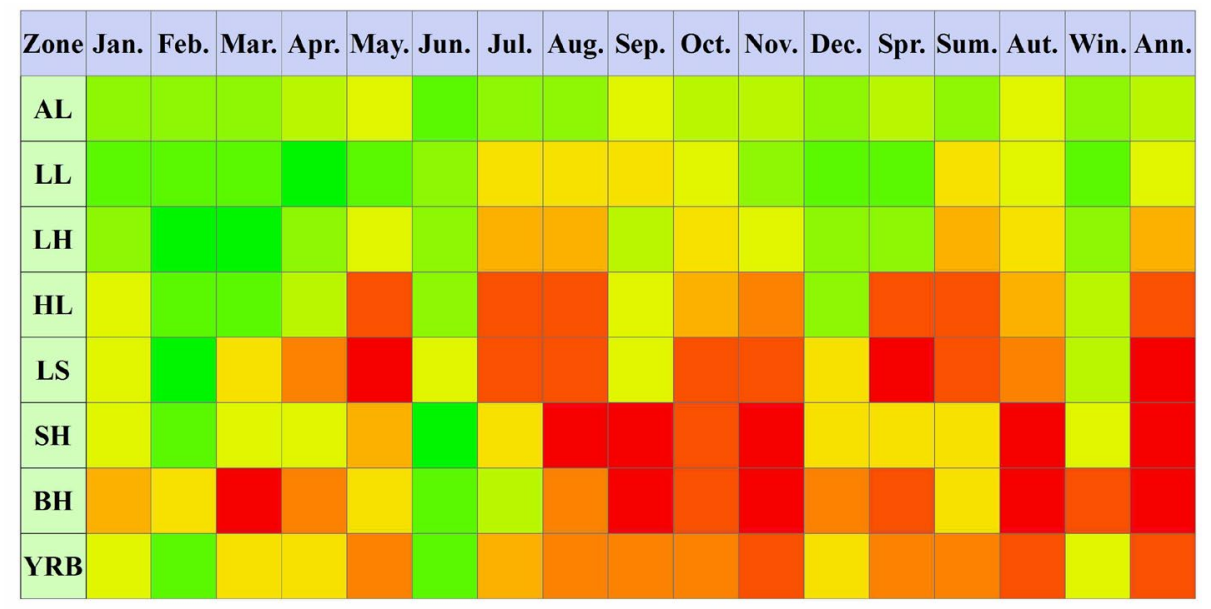

Zs values of SSI

$\begin{array}{lllllllllll}-1.83 & -1.51 & -1.29 & -1.15 & -1.01 & -0.85 & -0.61 & -0.37 & 0.00 & 0.42 & 1.14\end{array}$

Fig. 5. $Z_{s}$ values of SSI in the YRB during 1961-2015.

\subsection{Return period of hydrological drought}

\subsubsection{Marginal distribution functions}


Table 4 indicates that the theoretical distribution of drought duration and severity fits well, with smaller statistic $d$ value, statistic $a$ value, and AIC value. Meanwhile, all of the optimal distributions passed the significance test of $\alpha=0.05$. Therefore, it can be concluded that both drought duration and severity conform to the optimal distribution. Among the 16 selected optimal distribution functions, there were 6 Log-L, 5 GEV, 3 Logn, and 2 Wb1 distribution. Similar to streamflow distribution, most of the optimal marginal distribution functions of drought duration and severity were Log-L and GEV distributions in the YRB. Before the joint distribution function was established, Kendall rank correlation coefficient $\tau$ and Spearman rank correlation coefficient $\rho_{s}$ were also adopted to test the correlation between drought duration and severity. The calculated $\tau$ and $\rho_{s}$ values can represent the correlation degree between drought duration and severity (Mirabbasi et al., 2012; Li et al., 2015). As shown in Table 4, the $\tau$ values were all above 0.69 , and reached the maximum value $(0.83)$ in $\mathrm{SH}$. And the $\rho_{s}$ values were all above 0.78 , and reached the maximum value (0.94) in SH. All correlation coefficients passed the significance test of $\alpha=0.01$, which indicated that drought duration and severity were highly correlated. Thus, copula function can be used to determine the joint distribution function of drought duration and severity in the YRB.

\section{Table 4}

Determination of the optimal marginal distribution function. “**” denote that the correlation coefficients pass the significance test of $\alpha=0.01$.

\begin{tabular}{|c|c|c|c|c|c|c|c|c|c|}
\hline Zone & $\begin{array}{c}\text { Drought } \\
\text { characteristics }\end{array}$ & $\begin{array}{c}\text { Optimal } \\
\text { distribution }\end{array}$ & Parameters & $p$ & $d$ & $a$ & $\mathrm{AIC}$ & $\begin{array}{c}\text { Kendall rank } \\
\text { correlation } \\
\text { coefficient } \tau\end{array}$ & $\begin{array}{c}\text { Spearman rank } \\
\text { correlation } \\
\text { coefficient } \rho_{s}\end{array}$ \\
\hline \multirow{2}{*}{$\mathrm{AL}$} & Duration & GEV & $k=0.28, \sigma=4.06, \mu=5.21$ & 0.32 & 0.17 & 0.43 & -171.29 & \multirow{2}{*}{$0.71^{* *}$} & \multirow{2}{*}{$0.80^{* *}$} \\
\hline & Severity & GEV & $k=0.37, \sigma=3.32, \mu=3.44$ & 0.96 & 0.09 & 0.29 & -193.75 & & \\
\hline \multirow{2}{*}{ LL } & Duration & GEV & $k=0.65, \sigma=2.04, \mu=3.04$ & 0.69 & 0.12 & 0.45 & -158.43 & \multirow{2}{*}{$0.82^{* *}$} & \multirow{2}{*}{$0.93^{* *}$} \\
\hline & Severity & Log-L & $\alpha=0.99, \beta=1.78, \gamma=0.53$ & 0.99 & 0.07 & 0.89 & -203.06 & & \\
\hline \multirow{2}{*}{ LH } & Duration & Log-L & $\alpha=1.80, \beta=2.86, \gamma=0.81$ & 0.22 & 0.15 & 0.93 & -202.32 & \multirow{2}{*}{$0.72^{* *}$} & \multirow{2}{*}{$0.85^{* *}$} \\
\hline & Severity & Log-L & $\alpha=1.45, \beta=2.29, \gamma=0.51$ & 0.97 & 0.08 & 0.36 & -270.36 & & \\
\hline
\end{tabular}




\begin{tabular}{|c|c|c|c|c|c|c|c|c|c|}
\hline \multirow{2}{*}{ HL } & Duration & Log-L & $\alpha=1.25, \beta=2.45, \gamma=0.94$ & 0.13 & 0.18 & 0.78 & -147.02 & \multirow{2}{*}{$0.78^{* *}$} & \multirow{2}{*}{$0.91^{* *}$} \\
\hline & Severity & $\mathrm{Wbl}$ & $\alpha=0.69, \beta=3.60, \gamma=0.55$ & 0.94 & 0.08 & 1.25 & -221.21 & & \\
\hline \multirow{2}{*}{ LS } & Duration & Log-L & $\alpha=1.19, \beta=3.09, \gamma=0.93$ & 0.64 & 0.13 & 0.82 & -151.67 & \multirow{2}{*}{$0.73^{* *}$} & \multirow{2}{*}{$0.86^{* *}$} \\
\hline & Severity & Logn & $\mu=0.86, \sigma=1.52, \gamma=0.46$ & 0.89 & 0.09 & 0.33 & -182.36 & & \\
\hline \multirow{2}{*}{ SH } & Duration & Logn & $\mu=1.28, \sigma=0.98, \gamma=0.53$ & 0.75 & 0.10 & 0.49 & -199.38 & \multirow{2}{*}{$0.83^{* *}$} & \multirow[b]{2}{*}{$0.94^{* *}$} \\
\hline & Severity & $\mathrm{Wbl}$ & $\alpha=0.73, \beta=4.82, \gamma=0.51$ & 0.95 & 0.08 & 1.37 & -254.93 & & \\
\hline \multirow[b]{2}{*}{ BH } & Duration & Logn & $\mu=1.22, \sigma=1.14, \gamma=0.66$ & 0.62 & 0.13 & 0.51 & -155.64 & \multirow{2}{*}{$0.69^{* *}$} & \multirow{2}{*}{$0.78^{* *}$} \\
\hline & Severity & GEV & $k=0.65, \sigma=2.25, \mu=2.06$ & 0.86 & 0.10 & 0.53 & -188.50 & & \\
\hline \multirow{2}{*}{ YRB } & Duration & $\log -\mathrm{L}$ & $\alpha=1.54, \beta=3.68, \gamma=0.88$ & 0.78 & 0.11 & 0.41 & -165.03 & \multirow{2}{*}{$0.81^{* *}$} & \multirow{2}{*}{$0.93^{* *}$} \\
\hline & Severity & GEV & $k=0.66, \sigma=2.20, \mu=2.18$ & 0.78 & 0.11 & 0.31 & -208.03 & & \\
\hline
\end{tabular}

389 4.2.2. Copula models

390 Table 5 shows the GOF evaluation of different copula functions in the YRB.

391 Apparently, all the GOF evaluation indicators of the selected optimal copula met the

392 requirements. Therefore, the selected optimal copula functions were regarded as the joint

393 distribution functions of drought duration and severity in the YRB. From the obtained

394 copula functions, we can see that the optimal copula was Frank-copula for six subzones (AL,

395 LL, LH, LS, SH, and BH) and the whole basin. In conclusion, Frank-copula was considered

396 to be the best-fitted copula in the YRB.

\section{$397 \quad$ Table 5}

398 Goodness of fit (GOF) evaluation of different copula functions in the YRB. The bold letters

399 represent the selected optimal copula functions.

\begin{tabular}{|c|c|c|c|c|c|c|c|c|c|c|c|c|c|c|c|c|}
\hline \multirow{2}{*}{ Zone } & \multicolumn{3}{|c|}{ Normal-copula } & \multicolumn{3}{|c|}{ t-copula } & \multicolumn{3}{|c|}{ Clayton-copula } & \multicolumn{3}{|c|}{ Frank-copula } & \multicolumn{3}{|c|}{ Gumbel-copula } & \multirow{2}{*}{$\theta$} \\
\hline & RMSE & $\mathrm{AIC}$ & $\mathrm{BIC}$ & RMSE & $\mathrm{AIC}$ & $\mathrm{BIC}$ & RMSE & $\mathrm{AIC}$ & $\mathrm{BIC}$ & RMSE & $\mathrm{AIC}$ & $\mathrm{BIC}$ & RMSE & $\mathrm{AIC}$ & $\mathrm{BIC}$ & \\
\hline $\mathrm{AL}$ & 0.04 & -324.87 & -322.92 & 0.04 & -336.12 & -329.70 & 0.06 & -288.96 & -287.00 & 0.03 & -337.52 & -334.17 & 0.04 & -331.01 & -329.06 & 10.55 \\
\hline LL & 0.05 & -215.80 & -213.94 & 0.05 & -215.61 & -210.31 & 0.07 & -190.91 & -189.23 & 0.04 & -216.99 & -215.10 & 0.05 & -215.70 & -213.66 & 15.11 \\
\hline LH & 0.14 & -316.46 & -314.06 & 0.17 & -285.37 & -278.50 & 0.18 & -278.23 & -275.83 & 0.13 & -317.38 & -314.99 & 0.15 & -302.77 & -300.37 & 6.05 \\
\hline HL & 0.05 & -416.06 & -413.35 & 0.06 & -410.85 & -408.54 & 0.07 & -381.65 & -379.35 & 0.06 & -415.66 & -409.35 & 0.06 & -411.41 & -409.10 & 0.91 \\
\hline LS & 0.10 & -286.73 & -284.56 & 0.08 & -318.76 & -313.70 & 0.17 & -224.50 & -222.34 & 0.07 & -322.16 & -319.99 & 0.08 & -315.86 & -311.60 & 9.91 \\
\hline SH & 0.07 & -329.29 & -327.17 & 0.06 & -336.80 & -332.02 & 0.10 & -281.71 & -279.59 & 0.05 & -350.30 & -348.19 & 0.06 & -334.14 & -329.96 & 14.75 \\
\hline $\mathrm{BH}$ & 0.04 & -289.02 & -287.17 & 0.04 & -294.08 & -287.18 & 0.05 & -267.85 & -266.02 & 0.03 & -297.27 & -295.44 & 0.04 & -289.01 & -286.65 & 9.89 \\
\hline YRB & 0.06 & -287.05 & -181.41 & 0.06 & -288.59 & -200.11 & 0.08 & -254.42 & -159.07 & 0.05 & -291.62 & -208.63 & 0.06 & -285.89 & -162.30 & 14.47 \\
\hline
\end{tabular}

401 Fig. 6 illustrates the return period levels based on the selected optimal copula. Among

402 the selected optimal copulas, there were seven Frank-copulas and one Normal-copula.

403 Based on the optimized run theory, the number of identified drought events was 31 in the 
YRB during 1961-2015 (Fig. 6h). In AL, LL, LH, HL, LS, SH, and BH, the number of identified drought events was $31,30,45,39,31,39$ and 31 , respectively. In the whole basin scale, the most severe drought occurred from November 1996 to June 1999, with drought duration of 32 months, drought severity of 43.29, and drought return period exceeding 20 years (23.26 years). Additionally, the average drought duration and severity were 6.52 months and 5.47. Within the range of drought duration less than 10 months, and drought severity less than 10, a total of 26 drought events occurred in the YRB, with drought return period ranging from 0.53 to 4.04 years. With the enhancement of drought duration and severity, the frequency of drought events decreased, and the drought return period increased gradually in the YRB. The drought return period in each subzone is demonstrated in Figs. 6a-g. In AL, LL, LH, HL, LS, SH, and BH, the identified longest drought duration was 38 months, 28 months, 31 months, 27 months, 20 months, 31 months and 20 months, respectively; and the average drought duration was 9.13 months, 5.83 months, 5.14 months, 6.33 months, 5.81 months, 6.21 months and 5.52 months, respectively. In these subzones, the identified maximum drought severity was $42.30,40.77,37.41,33.99,27.73,40.47$ and 32.90, respectively; and the average drought severity was $7.21,5.24,4.70,6.11,5.09,6.13$ and 5.06, respectively. Meanwhile, the longest drought duration corresponded to the maximum drought severity in all subzones. In addition, there were two drought events in $\mathrm{LH}$, one drought event in $\mathrm{AL}$, and one drought event in $\mathrm{SH}$, with drought return period exceeding 25 years. The average drought duration and severity in each subzone was close to each other, except for the values in AL. The average drought duration reached the maximum value (6.33 months) in HL, and the minimum value (5.14 months) in LH, with a difference of only 1.19 months. And the average drought severity reached the maximum value (6.13) in $\mathrm{SH}$, and the minimum value (4.70) in LH, with a difference of only 1.43 .

With the enhancement of drought duration and severity, the corresponding drought return period increased, and drought disaster tended to be serious. Drought occurred more 
frequently with return period less than 10 years in the YRB. Based on the MMK trend test method, the trend characteristic $Z_{s}$ values of drought duration and severity were all greater than zero, which indicated that the drought duration and severity were also increasing in recent decades. In conclusion, the combination of run theory and copula can better depict the drought characteristics in the YRB.
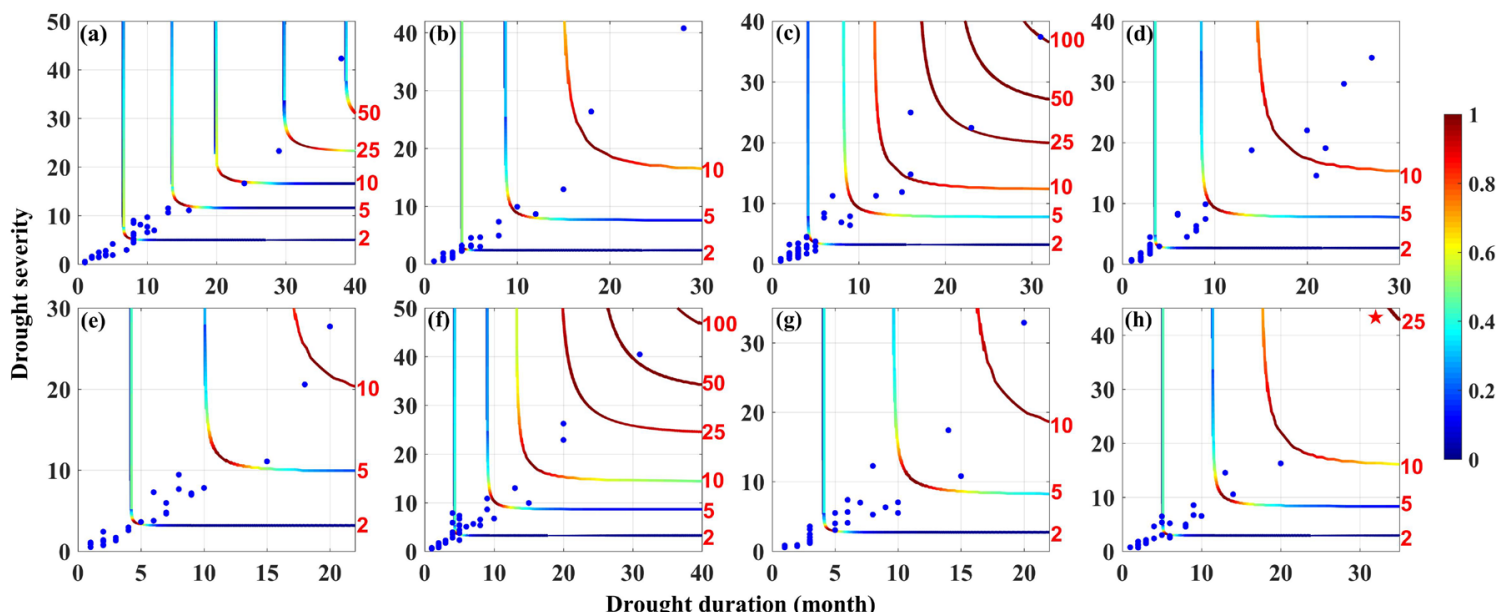

Fig. 6. Drought return period isolines are color coded with joint density levels with

blue representing lower densities and red denoting higher densities. Blue dots show

hydrological drought events.

shows the most severe drought event (1996-1999)

in the whole basin.

\subsection{The relationships between hydrological and meteorological drought}

Fig. 7 indicates the cross wavelet energy spectrum of monthly SSI and SPEI sequences. In order to avoid boundary effect and high frequency false information of the wavelet transform, the thin solid line in the figure is the boundary of the cone of influence (COI), with the effective spectral region within it. In the whole basin scale, there were three significant resonance periods between SSI and SPEI at the $95 \%$ confidence level, with a 30-48 month signal from 1965 to 1969 , a 64 month signal from 1986 to 1989 , and a 10-14 month signal from 1990 to 1992 (Fig. 7h). Meanwhile, the phase angle relationships indicated that SSI was positively correlated with SPEI and lagged behind SPEI variations. To gain additional insights, we compared the Pearson correlation coefficients $r$ and 
Spearman correlation coefficients $\rho_{s}$ between the monthly SSI and SPEI in the whole study period (1961-2015) and the period with significant resonance period. During 1961-2015, the $r$ and $\rho_{s}$ values between SSI and SPEI were 0.22 and 0.20 . However, the $r$ and $\rho_{s}$ values were 0.43 and 0.42 during $1965-1969,0.45$ and 0.44 during 1986-1989, and 0.57 and 0.54 during 1990-1992, respectively. It can be seen that the correlation coefficient was obviously improved between SSI and SPEI in the significant resonance periods based on cross wavelet transform, demonstrating the importance of considering various time scales when investigating the relationships between hydrological and meteorological drought. Additionally, there were short-term intermittent oscillation periods of 1-8 months between SSI and SPEI from 1961 to 2015. Figs. 7a-g exhibit the cross wavelet energy spectrum of monthly SSI and SPEI sequences in each subzone. The time-frequency structures of SSI and SPEI had certain similarity in each subzone, whilst a strong correlation appeared before 1970 with a period of $30-48$ months.
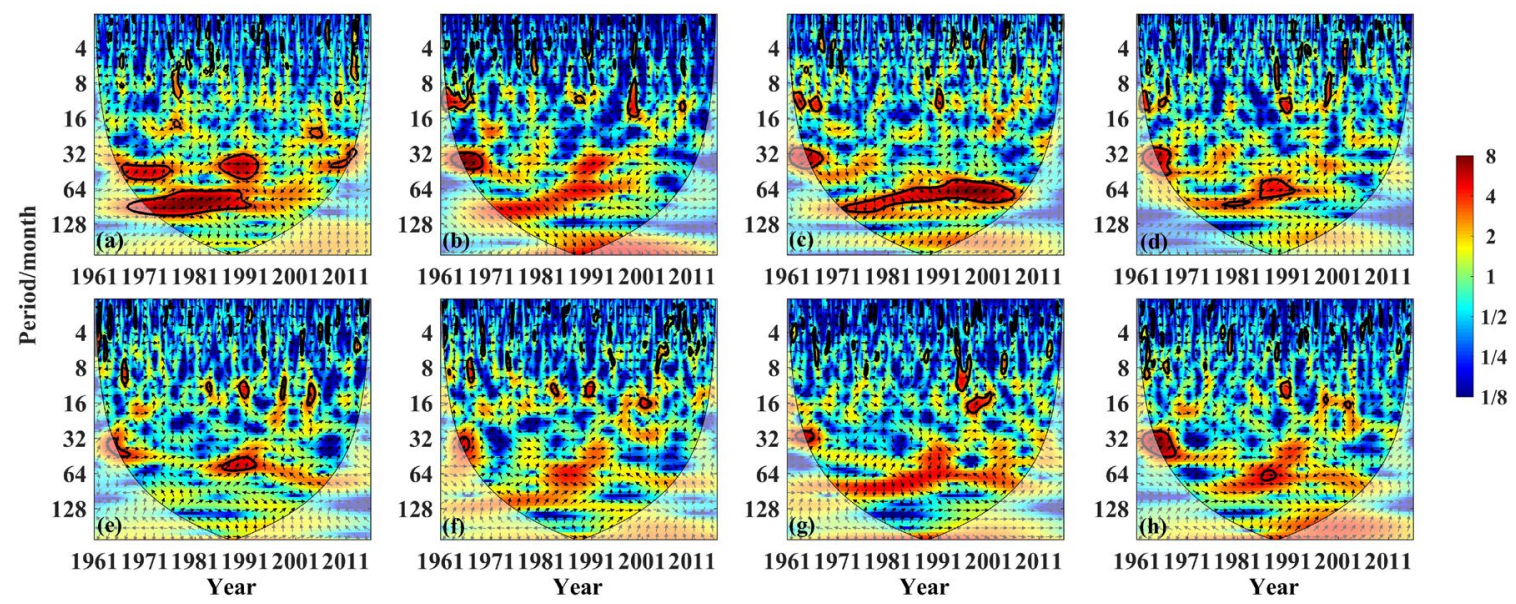

Fig. 7. The cross wavelet transform (XWT) between the monthly SSI and SPEI series during 1961-2015. The 95\% confidence level against red noise is exhibited as a thick contour, and the relative phase relationship is denoted as arrows (with negative correlations pointing left, and positive associations pointing right). The color bar on the right denotes the wavelet energy. 
Fig. 8 shows the wavelet coherence of the monthly SSI and SPEI sequences, which

470

471

472

473

474

475

476

477

478

479

480

481

482

483

484

485

486

487

488

can reflect the common characteristics and significant correlation between the two sequences in the low energy region. In the whole basin scale, SSI had a statistically significant positive correlation with SPEI at the 95\% confidence level, with a $26-60$ month signal from 1964 to 1977 , a 8-16 month signal from 1970 to 1978 , a 10-16 month signal from 1983 to 1987 , a 8-30 month signal from 1989 to 2001 , a $16-30$ month signal from 2000 to 2006, and a 18-34 month signal from 2008 to 2013 (Fig. 8h). Figs. 8a-g exhibit the wavelet coherence of monthly SSI and SPEI sequences in each subzone, with different correlations in both time and frequency domains. In summary, cross wavelet energy spectrum and wavelet coherence can better reflect the relationships and the detailed characteristics of oscillation period varying with time, and can deeply reveal the internal correlation between hydrological and meteorological drought in the YRB. There was a positive correlation between hydrological and meteorological drought, indicating that meteorological drought could promote the development of hydrological drought, and the occurrence of hydrological drought had a certain retardation time compared with meteorological drought.
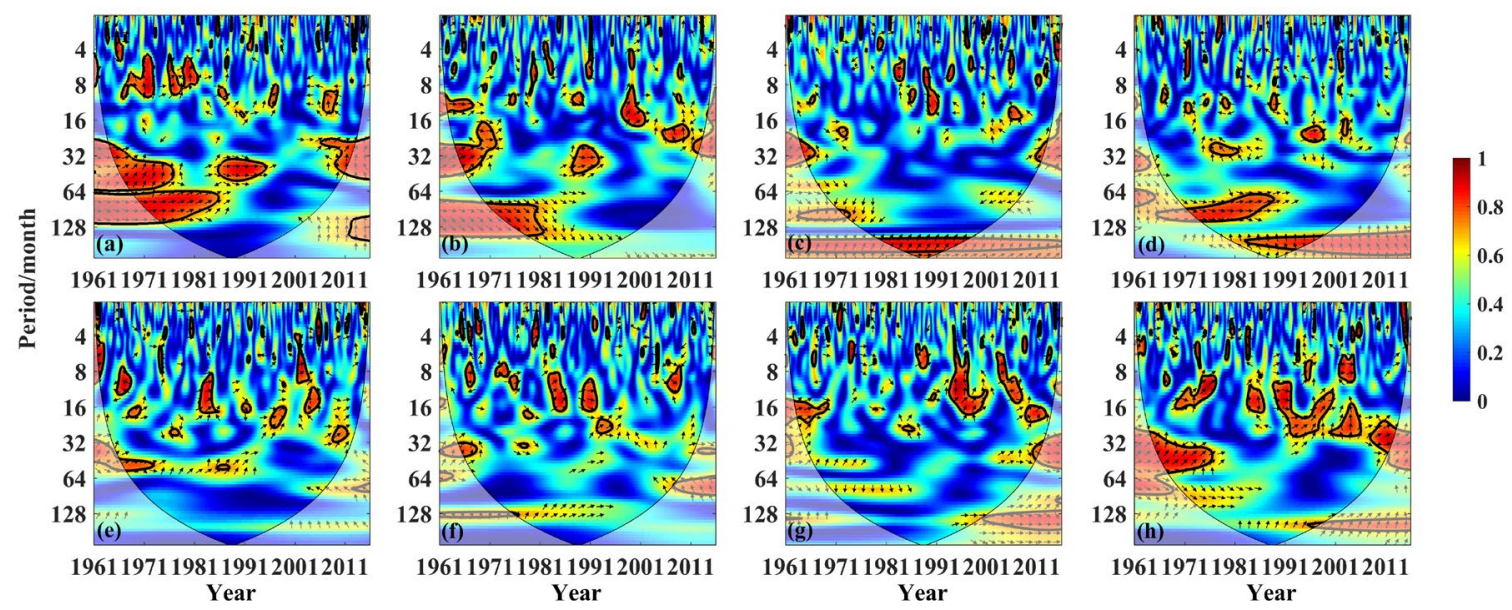

Fig. 8. The wavelet coherence (WTC) between the monthly SSI and SPEI series
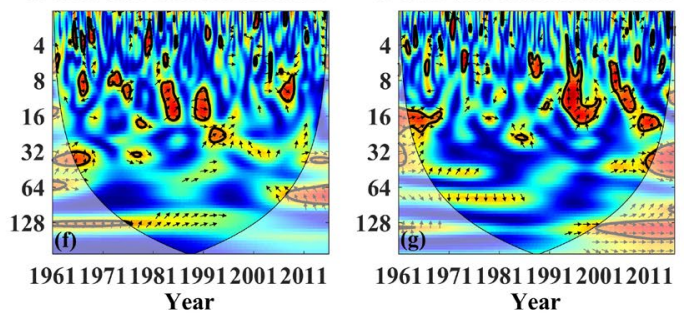

0.6

during 1961-2015. The 95\% confidence level against red noise is exhibited as a thick contour, and the relative phase relationship is denoted as arrows (with 
negative correlations pointing left, and positive associations pointing right). The color bar on the right denotes the wavelet energy.

491

492

\section{Discussion}

\subsection{The propagation time of hydrological drought from upstream to downstream}

The SSI series at various time scales (spanning 1-24 months) in the upstream were cross-correlated with the monthly SSI series (SSI-1) in the downstream to investigate the propagation of hydrological drought (Fig. 9). Subsequently, the propagation time can be obtained from the maximum correlation coefficients between SSI in the downstream and SSI at different time scales in the upstream. From AL to LL, LL to LH, LH to HL, HL to LS, LS to $\mathrm{SH}, \mathrm{SH}$ to $\mathrm{BH}$, the propagation time of hydrological drought was 2 months, 2 months, 1 month, 1 month, 1 month and 2 months, respectively. It is useful to investigate the propagation time of hydrological drought from upstream to downstream, which can help us to predict the possible occurrence time of hydrological drought in the downstream when the hydrological drought occurs in the upstream, and to timely formulate the drought prevention measures to reduce the impact of the hydrological drought.

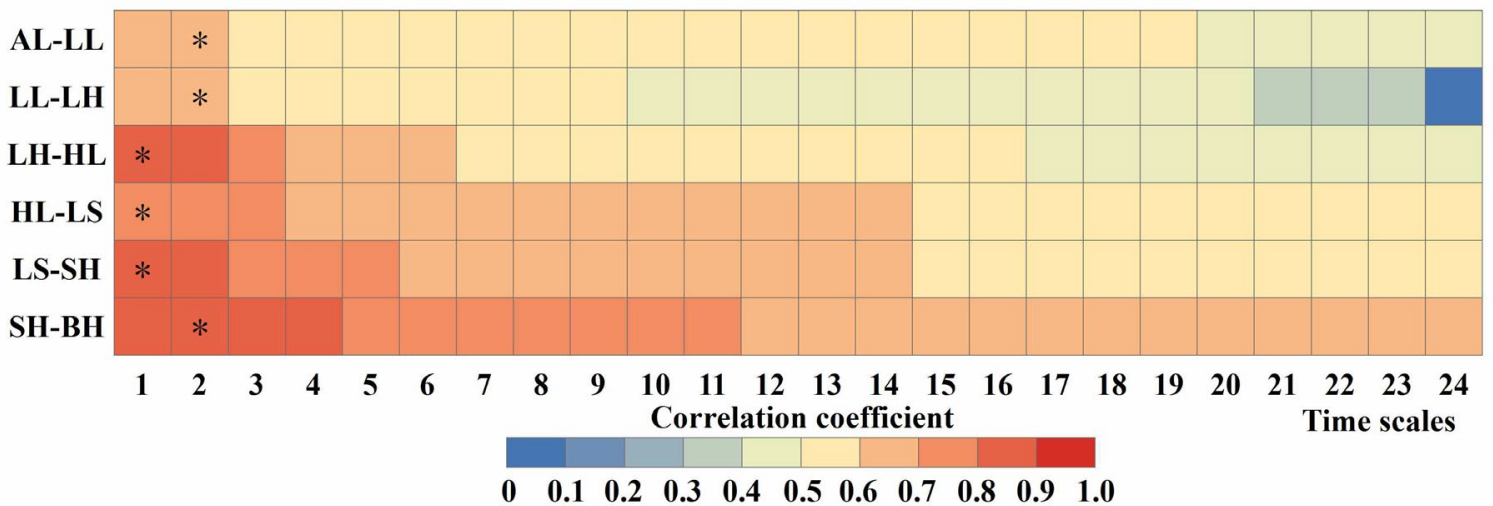

Fig. 9. The correlation coefficients between monthly SSI in the downstream and SSI at various time scales in the upstream. “*” represents the propagation time corresponding to the maximum correlation coefficient.

\subsection{The propagation time from meteorological to hydrological drought}


The development of meteorological drought caused by decreased precipitation will reduce surface streamflow and induce hydrological drought. Hydrological drought is the continuation and development of meteorological drought, and its evolution characteristics are closely related to meteorological drought (Wu et al., 2018b). Therefore, the investigation of the propagation time from meteorological to hydrological drought can deepen the understanding of the causes and characteristics of hydrological drought, and also provide a reference for the early warning of hydrological drought in the YRB (Wu et al., 2018c). The SPEI series at various time scales (spanning 1-24 months) were cross-correlated with the monthly SSI series (SSI-1) to investigate the most appropriate accumulation period for propagation from meteorological to hydrological drought. Fig. 10 shows the correlation coefficients between SSI-1 and SPEI at various time scales. The hydrological drought had time lag effect on meteorological drought, with different time-lags in each subzone of the YRB. The propagation time from meteorological to hydrological drought can be obtained from the maximum correlation coefficients $(\mathrm{P}<0.01)$ between SSI and SPEI at different time scales. The correlation coefficient was 0.266 and 0.345 at the significance level of 0.05 and 0.01 . In the whole basin scale, the propagation time from January to December was 12 months, 12 months, 6 months, 7 months, 7 months, 3 months, 4 months, 3 months, 11 months, 10 months, 9 months and 10 months, respectively, and the corresponding correlation coefficient was $0.48,0.59,0.68,0.67,0.72$, $0.77,0.79,0.79,0.73,0.76,0.69$ and 0.60 , respectively (Fig. 10h). Figs. 10a-g exhibit the propagation time from meteorological to hydrological drought in each subzone of the YRB. In summary, the propagation time was shorter in summer (approximately 3 months) and longer in winter (approximately 12 months). SSI was mostly positively correlated with SPEI at different time scales, with higher correlation coefficient in summer and lower in winter. 

characteristics and spatial patterns, which is primarily due to the highly fragile ecology and environment in the YRB (Liang et al., 2015). It takes time for meteorological drought to develop into hydrological drought in the YRB. This is because the change of surface streamflow caused by meteorological drought takes a period of time to accumulate and develop, which is consistent with the result of Leng et al. (2015). Because of the highest temperature and relatively high crop water requirement in summer, water sources in rivers may be used to supplement irrigation water when meteorological drought occurs. Therefore, meteorological drought is easy to promote the occurrence of hydrological drought with the shortest propagation time in summer. Furthermore, evapotranspiration is also greater in summer than in the other seasons, which may contribute to the shorter summer propagation time (Wu et al., 2018c). In winter, the relatively long propagation time is most likely due to snowmelt (Huang et al., 2017). Since frequent precipitation in summer and less precipitation in winter, the correlation between SSI and SPEI is higher in summer and lower in winter in the YRB (Zhang et al., 2014).
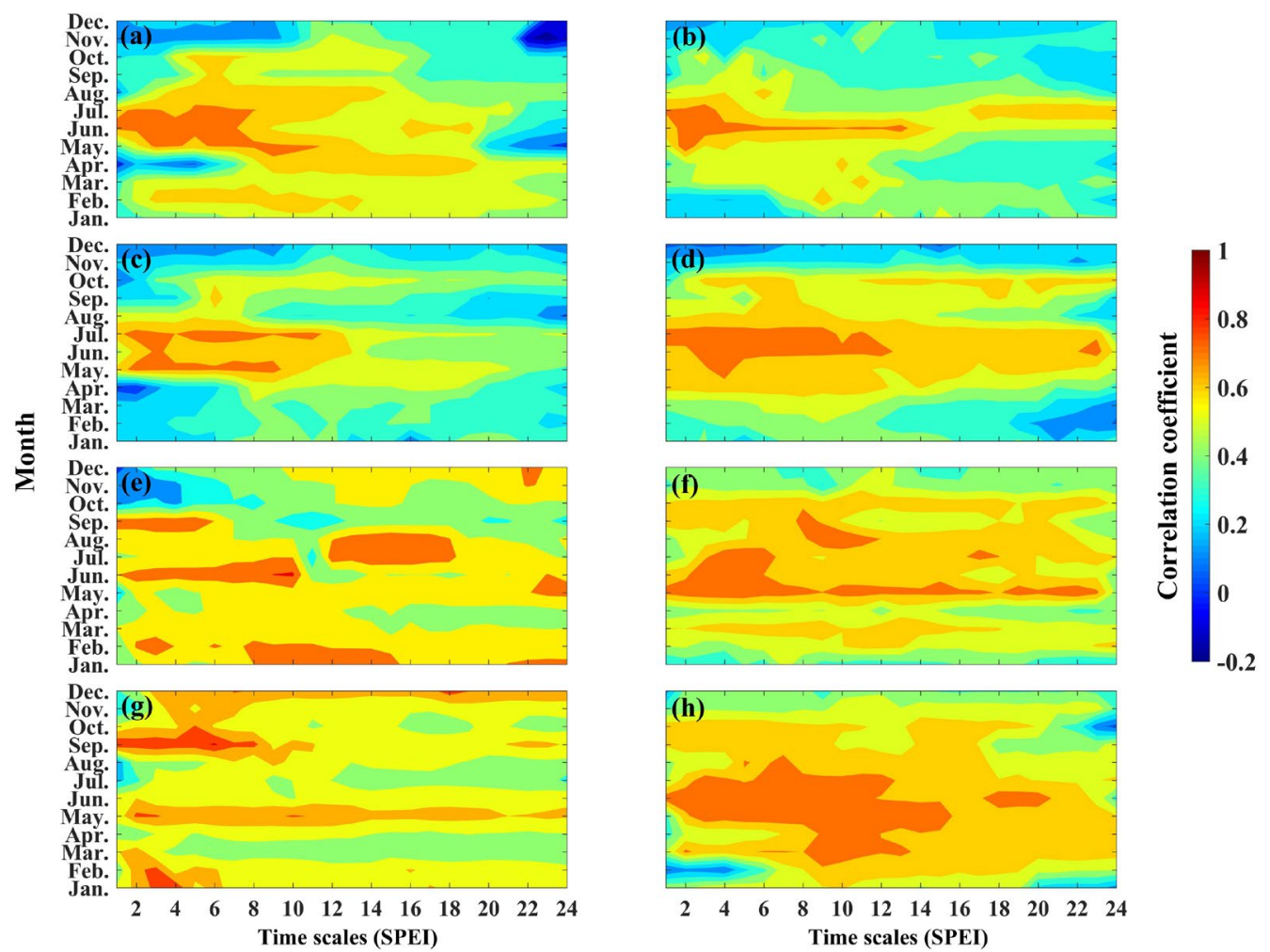
Fig. 10. The correlation coefficients between monthly SSI and SPEI at various time scales in the YRB.

\subsection{Effects of climate change and human activities}

There are many reasons for the development of hydrological drought in the YRB, mainly due to the effects of climate change and human activities. In the aspect of climate change, the meteorological drought showed an increasing trend from 1961 to 2015, especially since the 1990 s, which also led to the aggravation of hydrological drought in the YRB. In recent years, the precipitation showed a downward trend $(-5.123 \mathrm{~mm} / 10 \mathrm{a})$, and the temperature showed an upward trend $\left(0.316{ }^{\circ} \mathrm{C} / 10 \mathrm{a}\right)$ in the YRB (Zhang et al., 2014; Wang et al., 2018b). Especially since the 1990s, the rise of temperature has accelerated significantly. Thus, intensified warming and diminished precipitation have increased the severity of hydrological drought in the YRB. Additionally, global warming aggravates the El Niño-Southern Oscillation (ENSO) phenomenon, resulting in uneven spatial and temporal distribution of precipitation in the YRB, and raising the possibility of serious hydrological drought disasters (Wang et al., 2013; Miao et al., 2016). In addition to the factors of climate change, human activities have also affected the development of hydrological drought by changing the underlying surface of river basins in recent years. Sustained population growth and rapid economic development have resulted in a sustained increase in industrial and agricultural production and water consumption for people's livelihood, resulting in the over-exploitation of water resources and a series of ecological environment deterioration phenomena, such as river cut-off, vegetation coverage reduction, and groundwater level decline, which will also promote the development of hydrological drought in the YRB (Zhu and Chang, 2017). The irrigation area of the YRB increased from 0.8 million $\mathrm{hm}^{2}$ in 1950 to 7.33 million $\mathrm{hm}^{2}$ at the end of 2000 (Hu et al., 2013). Thus, the expansion of irrigation area means subtractions of water have greatly increased, which have 
resulted in the decline of streamflow (Fu et al., 2004; Zhao et al., 2017). Furthermore, the total amount of water resources is not abundant in the YRB. During the crop water demand season, people over-exploit the water resources for irrigation, which will lead to more acute contradiction between supply and demand of water resources and then trigger hydrological drought (Shi et al., 2017). Changes of land use have also increased water consumption, which have aggravated hydrological drought in the YRB (Li et al., 2001). Liu et al. (2016) quantitatively analyzed the impacts of climate change and human activities on runoff in major river basins of China, and found that climate change reduced the runoff depth by more than $40 \mathrm{~mm}$ and human activities reduced runoff depth by $19.4 \mathrm{~mm}$ in the YRB. Thus, the reduction of runoff also promoted the formation of hydrological drought. Huang et al. (2015) indicated that the temperature will rise significantly in the YRB, which may lead to the reduction of water resources and the aggravation of hydrological drought in the future. Therefore, water resources should be utilized economically and managed effectively. Meanwhile, large-scale water conservancy projects should be given full play to intercept flood and regulate runoff, which will contribute to improving the drought resistance level of the YRB.

\subsection{Advantages and Limitations}

In a small river basin, the distribution of long-term streamflow data is generally Gamma distribution (Nalbantis and Tsakiris, 2009). However, because of the large geographical scope of the YRB, the streamflow distribution will exhibit regional differences, thus it is necessary to check the probability distribution of streamflow (Peña-Gallardo et al., 2019). Compared with simply considering the streamflow distribution as a Gamma distribution, in this study, the SSI was calculated based on the optimal distribution function of streamflow, which can better reflect the hydrological drought characteristics of the YRB. Additionally, most of the optimal distribution functions of streamflow calculated were GEV or Log-L distributions. Vicente-Serrano et al. (2012) also 
indicated that the optimal distribution functions of streamflow were GEV or Log-L distributions, which was consistent with the research results in this paper. Based on the MMK trend test method, drought generally showed a non-significant upward trend in the YRB, which was consistent with the conclusions in Section 4.1. Based on the optimized run theory, a total of 31 drought events occurred in the YRB during 1961-2015. Among them, 14 droughts occurred before the 1990s with an average drought duration and severity of 5.36 months and 3.79, and 17 droughts occurred since the 1990s with an average drought duration and severity of 7.47 months and 6.85. It can be seen that drought had become more serious since the 1990s, which was consistent with the temporal evolution characteristics of drought in Section 4.1. From the duration period of the identified drought events, it can be concluded that the year of 1997 was included in the period when the worst droughts occurred, indicating that drought occurred most seriously in 1997 in the YRB. Analyzing the change process of this drought event, we found that drought began in November 1996 $(\mathrm{SSI}=0.66)$, then gradually intensified, and reached its worst period in November 1997, with the minimum SSI value of -2.75 . And the drought was relatively serious from September to December 1997, with cumulative SSI value of -10.01 . The phenomenon of river cut-off has become gradually serious since the 1990s. Especially in 1997, the longest river cut-off event in history occurred in the lower reaches of the YRB (226 days) (Huo et al., 1998). Moreover, since the establishment of China, the worst drought occurred in 1997 in the YRB, with the least annual precipitation $(350.92 \mathrm{~mm})$ and continuously high temperature in most areas (Wang et al., 2018b). Meanwhile, based on copula function, the worst drought occurred in 1997 with a return period of 23.26 years, which was consistent with the actual drought condition.

The results of copula GOF showed that the optimal copula function was Frank-copula in the YRB. Wang et al. (2017) also pointed out that Frank-copula had the best GOF and could be used as the joint distribution function of drought duration and severity in the YRB. 
Based on copula function, the return period of drought event can be obtained, which can well reflect the severity degree of drought in the YRB. At present, there are hundreds of copula functions available, but only a few are mature in practical application. In this paper, only five commonly used copula functions were discussed, and other copula types would be the focus of future research (Fenech et al., 2015). In addition, with the increase of characteristic variables in drought research, it is necessary to integrate more characteristic variables to establish joint functions among multiple variables, and the application of high-dimensional copula will become a new research direction in the future (Oh and Patton, 2016).

\section{Conclusions}

In this paper, SSI was selected as a hydrological drought index, and the evolution characteristics of hydrological drought were comprehensively evaluated in the YRB from 1961 to 2015. Based on run theory and copula function, the joint return period of hydrological drought duration and severity was quantitatively identified. Finally, the relationships between hydrological and meteorological drought were revealed by cross wavelet transform method in the YRB. From the results, major conclusions are given as follows:

(1) By fitting the monthly streamflow data, the optimal distribution function of streamflow can be obtained to calculate SSI. Drought showed an increasing trend in the YRB from 1961 to 2015, especially since the 1990s, with the worst drought occurred in 1997. By calculating SSI values at different time scales (1-24 months), it can be seen that drought showed an upward trend at all time scales, whilst the trend of drought aggravation was gradually obvious with the increase of time scales. The results of MMK trend test showed that the seasonal and annual drought was increasing, while the trend characteristics of drought were different in each subzone. 
(2) Based on run theory, the duration and severity of drought events were identified,

653

654

655

656

657

658

659

660

661

662

663

664

665

666

667

668

669

670

671

672

673

674

675

676

and the optimal marginal distribution functions were determined. Meanwhile, the K-S, A-D and AIC test method were adopted to test the fitting results, and the optimal distribution functions of drought duration and severity met the requirements. Drought duration and severity had a strong correlation, and the Kendall and Spearman rank correlation coefficients between them were all above 0.69 and 0.78 , respectively. Additionally, Frank-copula was considered to be the best-fitted copula function in the YRB. The most severe drought occurred from November 1996 to June 1999 in the YRB, with drought duration of 32 months, drought severity of 43.29, and drought return period exceeding 20 years (23.26 years). With the enhancement of drought duration and severity, the corresponding drought return period increased, and drought disaster tended to be serious.

(3) The cross wavelet transform and wavelet coherence can reveal the relationships between hydrological and meteorological drought in the YRB during 1961-2015. There were three significant resonance periods between SSI and SPEI at the 95\% confidence level, with a 30-48 month signal from 1965 to 1969, a 64 month signal from 1986 to 1989, and a 10-14 month signal from 1990 to 1992 . Meanwhile, the phase angle relationships indicated that SSI was positively correlated with SPEI and lagged behind SPEI.

\section{Acknowledgments}

This research was supported by National Key R\&D Program of China (2018YFC1508506), Key Scientific Research Projects of Henan Colleges and Universities (Grant No. 19A170014), Henan Province Scientific and Technological Project (Grant No. 172102410075), the Open Research Fund of the State Key Laboratory of Simulation and Regulation of Water Cycle in River Basin at the China Institute of Water Resources and Hydropower Research (IWHR-SKL-201701), the National Natural Science Foundation of 
China (51779093), and Science and technology project of Guizhou Province Water Resources Department (KT201705).

\section{References}

Ayantobo, O.O., Li, Y., Song, S.B., Javed, T., Yao, N., 2018. Probabilistic modelling of drought events in China via 2-dimensional joint copula. J. Hydrol. 559, 373-391.

Barker, L.J, Hannaford, J., Chiverton, A., Svensson, C., 2016. From meteorological to hydrological drought using standardised indicators. Hydrol. Earth Syst. Sci. 20, 2483-2505.

Bloomfield, J.P., Marchant, B.P., 2013. Analysis of groundwater drought building on the standardized precipitation index approach. Hydrol. Earth Syst. Sc. 17, 4769-4787.

Chen, X., Li, F.W., Feng, P., 2018. Spatiotemporal variation of hydrological drought based on the Optimal Standardized Streamflow Index in Luanhe River basin, China. Nat. Hazards 91, 155-178.

Clayton, D.G., 1978. A model for association in bivariate life tables and its application in epidemiological studies of familial tendency in chronic disease incidence. Biometrika $65,141-151$.

Dash, S.S., Sahoo, B., Raghuwanshi, N.S., 2019. A SWAT-Copula based approach for monitoring and assessment of drought propagation in an irrigation command. Ecol. Eng. 127, 417-430.

Esfahanian, E., Nejadhashemi, A.P., Abouali, M., Adhikari, U., Zhang, Z., Daneshvar, F., Herman, M.R., 2016. Development and evaluation of a comprehensive drought index. J. Env. Mgt. 185, 31-43.

Fan, L.L., Wang, H.R., Liu, Z.P., Li, N., 2018. Quantifying the relationship between drought and water scarcity using copulas: case study of Beijing-Tianjin-Hebei metropolitan areas in China. Water 10, 1622. 
Fenech, J.P., Vosgha, H., Shafik, S., 2015. Loan default correlation using an Archimedean copula approach: A case for recalibration. Econ. Model. 47, 340-354.

Fu, G.B., Chen, S.L., Liu, C.M., Shepard, D., 2004. Hydro-climatic trends of the Yellow River Basin for the last 50 years. Clim. Change 65, 149-178.

Grinsted, A., Moore, J.C., Jevrejeva, S., 2004. Application of the cross wavelet transform and wavelet coherence to geophysical time series. Nonlinear Proc. Geoph. 11, 561-566.

Hosking, J.R.M., 1990. L-moments: Analysis and estimation of distributions using linear combinations of order statistics. J. R. Stat. Soc. 52, 105-124.

Hosking, J.R.M., Wallis, J.R., Wood, E.F., 1985. Estimation of the generalized extreme-value distribution by the method of probability-weighted moments. Technometrics 27, 251-261.

Hosking, J.R.M., 1986. The theory of probability weighted moments. Research Rep. RC12210, IBM Research Div., Yorktown Heights.

Huang, S.Z., Chang, J.X., Leng, G.Y., Huang, Q., 2015. Integrated index for drought assessment based on variable fuzzy set theory: A case study in the Yellow River basin, China. J. Hydrol. 527, 608-618.

Huang, S.Z., Huang, Q., Zhang, H.B., Chen, Y.T., Leng, G.Y., 2016. Spatio-temporal changes in precipitation, temperature and their possibly changing relationship: A case study in the Wei River Basin, China. Int. J. Climatol. 36, 1160-1169.

Huang, S.Z., Li, P., Huang, Q., Leng, G.Y., Hou, B.B., Ma, L., 2017. The propagation from meteorological to hydrological drought and its potential influence factors. J. Hydrol. 547, 184-195.

Hu, C.H., Wang, J.J., Chai, X.L., Guan, X.J., 2013. Research advances of impacts of climate change on runoff of the Yellow River Basin. Meteorol. Environ. Sci. 36, $57-65$. 
Huo, S.Q., Wang, H.B., Peng, M.X., 1998. Analysis on No-flow in the Lower Yellow River in 1997. Yellow River 20, 1-3 (In Chinese).

Kao, S.C., Govindaraju, R.S., 2010. A copula-based joint deficit index for droughts. J. Hydrol. 380, 121-134.

Lai, C.G., Zhong, R.D., Wang, Z.L., Wu, X.Q., Chen, X.H., Wang, P., Lian, Y.Q., 2019. Monitoring hydrological drought using long-term satellite-based precipitation data. Sci. Total Environ. 649, 1198-1208.

Lee, T., Modarres, R., Ouarda, T.B.M.J., 2013. Data-based analysis of bivariate copula tail dependence for drought duration and severity. Hydrol. Processes 27, 1454-1463.

Leng, G.Y., Tang, Q.H., Rayburg, S., 2015. Climate change impacts on meteorological, agricultural and hydrological droughts in China. Global Planet. Change 126, 23-34.

Li, C., Singh, V.P., Mishra, A.K., 2013. A bivariate mixed distribution with a heavy-tailed component and its application to single-site daily rainfall simulation. Water Resour. Res. 49, 767-789.

Li, X.J., Peterson, J., Liu, G.J., Qian, L.X., 2001. Assessing regional sustainability: the case study of land use and land cover change in the middle Yiluo catchment of the Yellow River Basin, China. Appl. Geog. 21, 87-106.

Li, Y., Gu, W., Cui, W.J., Chang, Z.Y., Xu, Y.J., 2015. Exploration of copula function use in crop meteorological drought risk analysis: A case study of winter wheat in Beijing, China. Nat. Hazards 77, 1-15.

Liang, W., Bai, D., Wang, F.Y., Fu, B.J., Yan, J.P., Wang, S., Yang, Y.T., Long, D., Feng, M.Q., 2015. Quantifying the impacts of climate change and ecological restoration on streamflow changes based on a Budyko hydrological model in China's Loess Plateau. Water Resour. Res. 51, 6500-6519. 
Lin, Q.X., Wu, Z.Y., Singh, V.P., Sadeghi, S.H.R., He, H., Lu, G.H., 2017. Correlation between hydrological drought, climatic factors, reservoir operation, and vegetation cover in the Xijiang Basin, South China. J. Hydrol. 549, 512-524.

Liu, J.Y., Zhang, Q., Chen, X., Gu, X.H., 2016. Quantitative evaluations of human- and climate-induced impacts on hydrological processes of China. Acta Geogr. Sinica. 71, 1-11 (In Chinese).

Miao, C.Y., Sun, Q.H., Duan, Q.Y., Wang, Y.F., 2016. Joint analysis of changes in temperature and precipitation on the Loess Plateau during the period 1961-2011. Clim Dyn. 47, 3221-3234.

Mirabbasi, R., Fakheri-Fard, A., Dinpashoh, Y., 2012. Bivariate drought frequency analysis using the copula method. Theor. Appl. Climatol. 108, 191-206.

Mishra, A.K., Singh, V.P., 2010. A review of drought concepts. J. Hydrol. 391, 202-216.

Mishra, A.K., Singh, V.P., 2011. Drought modeling-A review. J. Hydrol. 403, 157-175.

Nalbantis, I., Tsakiris, G., 2009. Assessment of hydrological drought revisited. Water Resour. Manag. 23, 881-897.

Núñez, J., Rivera, D., Oyarzún, R., Arumí, J.L., 2014. On the use of Standardized Drought Indices under decadal climate variability: Critical assessment and drought policy implications. J. Hydrol. 517, 458-470.

Oh, D.H., Patton, A.J., 2016. High-dimensional copula-based distributions with mixed frequency data. J. Econometrics 193, 349-366.

Omer, A., Ma, Z.G., Zheng, Z.Y., Saleem, F., 2020. Natural and anthropogenic influences on the recent droughts in Yellow River Basin, China. Sci. Total Environ. 704, 135428.

Palmer, T.N., Räisänen, J., 2002. Quantifying the risk of extreme seasonal precipitation events in a changing climate. Nature $415,512-514$.

Pandey, R.P., Ramasastri, K.S., 2001. Relationship between the common climatic parameters and average drought frequency. Hydrol. Processes 15, 1019-1032. 
Peña-Gallardo, M., Vicente-Serrano, S.M., Hannaford, J., Lorenzo-Lacruz, J., Svoboda, M., Domínguez-Castro, F., Maneta, M., Tomas-Burguera, M., Kenawy, A.E., 2019. Complex influences of meteorological drought time-scales on hydrological droughts in natural basins of the contiguous Unites States. J. Hydrol. 568, 611-625.

Rivera, J.A., Penalba, O.C., Villalba, R., Araneo, D.C., 2017. Spatio-temporal patterns of the 2010-2015 extreme hydrological drought across the Central Andes, Argentina. Water 9,652 .

Sadegh, M., Ragno, E., AghaKouchak, A., 2017. Multivariate Copula Analysis Toolbox (MvCAT): Describing dependence and underlying uncertainty using a Bayesian framework. Water Resour. Res. 53, 1-18.

Salas, J.D., Fu, C., Cancelliere, A., Dustin, D., Bode, D., Pineda, A., Vincent, E., 2005. Characterizing the severity and risk of drought in the Poudre River, Colorado. J. Water Res. Plan. Man. 131, 383-393.

Sherly, M.A., Karmakar, S., Chan, T., Rau, C., 2016. Design rainfall framework using multivariate parametric-nonparametric approach. J. Hydrol. Eng. 21, 04015049.

Shi, H.L., Hu, C.H., Wang, Y.G., Liu, C., Li, H.M., 2017. Analyses of trends and causes for variations in runoff and sediment load of the Yellow River. Int. J. Sediment Res. 32, $171-179$.

Shiau, J.T., Feng, S., Nadarajah, S., 2007. Assessment of hydrological droughts for the Yellow River, China, using copulas. Hydrol. Process. 21, 2157-2163.

Shukla, S., Wood, A.W., 2008. Use of a standardized runoff index for characterizing hydrologic drought. Geophys. Res. Lett. 35, 1-7.

Singh, V.P., Guo, H., Yu, F.X., 1993. Parameter estimation for 3-parameter log-logistic distribution (LLD3) by Pome. Stoch. Hydrol. Hydraul. 7, 163-177.

Sklar M., 1959. Fonctions de répartition àn dimensions et leurs marges. Université Paris 8. 
Telesca, L., Lovallo, M., Lopez-Moreno, I., Vicente-Serrano, S., 2012. Investigation of scaling properties in monthly streamflow and Standardized Streamflow Index (SSI) time series in the Ebro basin (Spain). Physica A. 391, 1662-1678.

Thornthwaite, C.W., 1948. An approach toward a rational classification of climate. Geogr. Rev. 38, 55-94.

Tirivarombo, S., Osupile, D., Eliasson, P., 2018. Drought monitoring and analysis: Standardised Precipitation Evapotranspiration Index (SPEI) and Standardised Precipitation Index (SPI). Phys. Chem. Earth 106, 1-10.

Tosunoğlu, F., Onof, C., 2017. Joint modelling of drought characteristics derived from historical and synthetic rainfalls: Application of Generalized Linear Models and Copulas. J. Hydrol.-Regional Studies 14, 167-181.

Van Loon, A.F., Laaha, G., 2015. Hydrological drought severity explained by climate and catchment characteristics. J. Hydrol. 526, 3-14.

Vicente-Serrano, S.M., Beguería, S., López-Moreno, J.I., 2010. A multiscalar drought index sensitive to global warming: The Standardized Precipitation Evapotranspiration Index. J. Clim. 23, 1696-1718.

Vicente-Serrano, S.M., López-Moreno, J.I., 2005. Hydrological response to different time scales of climatological drought: an evaluation of the Standardized Precipitation Index in a mountainous Mediterranean basin. Hydrol. Earth Syst. Sci. 9, 523-533.

Vicente-Serrano, S.M., López-Moreno, J.I., Beguería, S., Lorenzo-Lacruz, J., Azorin-Molina, C., Morán-Tejeda, E., 2012. Accurate computation of a streamflow drought index. J. Hydrol. Eng. 17, 318-332.

Vidal, J.P., Martin, E., Franchistéguy, L., Habets, F., Soubeyroux, J.M., Blanchard, M., Baillon, M., 2010. Multilevel and multiscale drought reanalysis over France with the Safran-Isba-Modcou hydrometeorological suite. Hydrol. Earth Syst. Sci. 14, 459-478. 
Vyver, H.V.D., Bergh, J.V.D., 2018. The Gaussian copula model for the joint deficit index for droughts. J. Hydrol. 561, 987-999.

Wang, F., Wang, Z.M., Yang, H.B., Zhao, Y., Li, Z.H., Wu, J.P., 2018a. Capability of remotely sensed drought indices for representing the spatio-temporal variations of the meteorological droughts in the Yellow River Basin. Remote Sens. 10, 1834.

Wang, F., Wang, Z.M., Yang, H.B., Zhao, Y., 2018b. Study of the temporal and spatial patterns of drought in the Yellow River basin based on SPEI. Sci. China Earth Sci. 61, $1098-1111$.

Wang, F., Yang, H.B., Wang, Z.M., Zhang, Z.Z., Li, Z.H., 2019. Drought evaluation with CMORPH satellite precipitation data in the Yellow River Basin by using Gridded Standardized Precipitation Evapotranspiration Index. Remote Sens. 11, 485.

Wang, X.F., Zhang, Y., Feng, X.M., Feng, Y., Xue, Y.Y., Pan, N.Q., 2017. Analysis and application of drought characteristics based on run theory and Copula function. T. Chin. Soc. Agr. Eng. 33, 206-214 (In Chinese).

Wang, Y., Ding, Y.J., Ye, B.S., Liu, F.J., Wang, J., 2013. Contributions of climate and human activities to changes in runoff of the Yellow and Yangtze rivers from 1950 to 2008. Sci. China Earth Sci. 56, 1398-1412.

Wang, Y.X., Duan, L.M., Liu, T.X., Li, J.Z., Feng, P., 2020. A Non-stationary Standardized Streamflow Index for hydrological drought using climate and human-induced indices as covariates. Sci. Total Environ. 699, 134278.

Wu, J.F., Chen, X.W., Yao, H.X., Gao, L., Chen, Y., Liu, M.B., 2017. Non-linear relationship of hydrological drought responding to meteorological drought and impact of a large reservoir. J. Hydrol. 551, 495-507.

Wu, J.F., Liu, Z.Y., Yao, H.X., Chen, X.H., Chen, X.W., Zheng, Y.H., He, Y.H., 2018a. Impacts of reservoir operations on multi-scale correlations between hydrological drought and meteorological drought. J. Hydrol. 563, 726-736. 
Wu, J.W., Miao, C.Y., Tang, X., Duan, Q.Y., He, X.J., 2018b. A nonparametric standardized runoff index for characterizing hydrological drought on the Loess Plateau, China. Global Planet. Change 161, 53-65.

Wu, J.W., Miao, C.Y., Zheng, H.Y., Duan, Q.Y., Lei, X.H., Li, H., 2018c. Meteorological and hydrological drought on the Loess Plateau, China: Evolutionary characteristics, impact, and propagation. J. Geophys. Res-Atmos. 123, 11569-11584.

Xu, K., Yang, D.W., Xu, X.Y., Lei, H.M., 2015. Copula based drought frequency analysis considering the spatio-temporal variability in Southwest China. J. Hydrol. 527, $630-640$.

Xu, Y., Zhang, X., Wang, X., Hao, Z.C., Singh, V.P., Hao, F.H., 2019. Propagation from meteorological drought to hydrological drought under the impact of human activities: A case study in northern China. J. Hydrol. 579, 124147.

Yoo, J.Y., Kwon, H.H., Kim, T.W., Ahn, J.H., 2012. Drought frequency analysis using cluster analysis and bivariate probability distribution. J. Hydrol. 420-421, 102-111.

Zhang, B.Q., Zhao, X.N., Jin, J.M., Wu, P., 2015. Development and evaluation of a physically based multiscalar drought index: The Standardized Moisture Anomaly Index. J. Geophys. Res. 120, 11575-11588.

Zhang, Q., Peng, J.T., Singh, V.P., Li, J.F., Chen, Y.Q. 2014. Spatio-temporal variations of precipitation in arid and semiarid regions of China: The Yellow River basin as a case study. Global Planet. Change 114, 38-49.

Zhao, P.P., Lu, H.S., Fu, G.B., Zhu, Y.H., Su, J.B., Wang, J.Q., 2017. Uncertainty of hydrological drought characteristics with copula functions and probability distributions: A case study of Weihe River, China. Water 9, 334.

Zhu, Y.L., Chang, J.X., 2017. Application of VIC model based standardized drought index in the Yellow River Basin. J. Northwest A. F. Univ. 45, 203-212 (In Chinese). 
878 Zhu, Y., Liu, Y., Wang, W., Singh, V.P., Ma, X.Y., Yu, Z.G., 2019. Three dimensional 879 characterization of meteorological and hydrological droughts and their probabilistic links. J. Hydrol. 578, 124016. 